\title{
Eddy covariance measurements and parameterisation of traffic related particle emissions in an urban environment
}

\author{
E. M. Mårtensson ${ }^{1,2}$, E. D. Nilsson ${ }^{2}$, G. Buzorius ${ }^{3}$, and C. Johansson ${ }^{2,4}$ \\ ${ }^{1}$ Department of Meteorology, Stockholm University, 10691 Stockholm, Sweden \\ ${ }^{2}$ Section for Atmospheric Science, Department of Applied Environmental Research, Stockholm University, 10691 \\ Stockholm, Sweden \\ ${ }^{3}$ Department of Research, CIRPAS, Naval Postgraduate School, CA, USA \\ ${ }^{4}$ Environment and Health Protection Administration, Box 38 024, 10664 Stockholm, Sweden
}

Received: 9 May 2005 - Published in Atmos. Chem. Phys. Discuss.: 29 July 2005

Revised: 20 December 2005 - Accepted: 18 January 2006 - Published: 7 March 2006

\begin{abstract}
Urban aerosol sources are important due to the health effects of particles and their potential impact on climate. Our aim has been to quantify and parameterise the urban aerosol source number flux $F$ (particles $\mathrm{m}^{-2} \mathrm{~s}^{-1}$ ), in order to help improve how this source is represented in air quality and climate models. We applied an aerosol eddy covariance flux system $118.0 \mathrm{~m}$ above the city of Stockholm. This allowed us to measure the aerosol number flux for particles with diameters $>11 \mathrm{~nm}$. Upward source fluxes dominated completely over deposition fluxes in the collected dataset. Therefore, the measured fluxes were regarded as a good approximation of the aerosol surface sources. Upward fluxes were parameterised using a traffic activity (TA) database, which is based on traffic intensity measurements.

The footprint (area on the surface from which sources and sinks affect flux measurements, located at one point in space) of the eddy system covered road and building construction areas, forests and residential areas, as well as roads with high traffic density and smaller streets. We found pronounced diurnal cycles in the particle flux data, which were well correlated with the diurnal cycles in traffic activities, strongly supporting the conclusion that the major part of the aerosol fluxes was due to traffic emissions.

The emission factor for the fleet mix in the measurement area $E F_{f m}=1.4 \pm 0.1 \times 10^{14} \mathrm{veh}^{-1} \mathrm{~km}^{-1}$ was deduced. This agrees fairly well with other studies, although this study has an advantage of representing the actual effective emission from a mixed vehicle fleet. Emission from other sources, not traffic related, account for a $F_{0}=15 \pm 18 \times 10^{6} \mathrm{~m}^{-2} \mathrm{~s}^{-1}$. The urban aerosol source flux can then be written as $F=E F_{f m} T A+F_{0}$. In a second
\end{abstract}

Correspondence to: E. M. Mårtensson

(monica@misu.su.se) attempt to find a parameterisation, the friction velocity $U_{*}$ normalised with the average friction velocity $\overline{U_{*}}$ has been included, $F=E F_{f m} T A\left(\frac{U_{*}}{U_{*}}\right)^{0.4}+F_{0}$. This parameterisation results in a somewhat reduced emission factor, $1.3 \times 10^{14} \mathrm{veh}^{-1} \mathrm{~km}^{-1}$. When multiple linear regression have been used, two emission factors are found, one for light duty vehicles $E F_{\mathrm{LDV}}=0.3 \pm 0.3 \times 10^{14} \mathrm{veh}^{-1} \mathrm{~km}^{-1}$ and one for heavy-duty vehicles, $E F_{\mathrm{HDV}}=19.8 \pm 4.0 \times 10^{14} \mathrm{veh}^{-1} \mathrm{~km}^{-1}$, and $F_{0}=19 \pm 16 \times 10^{6} \mathrm{~m}^{-2} \mathrm{~s}^{-1}$. The results show that during weekdays $\sim 70-80 \%$ of the emissions came from HDV.

\section{Introduction}

Anthropogenic aerosol particles have the potential to influence climate directly through Mie-scattering and absorption and indirectly when they serve as cloud condensation nuclei $(\mathrm{CCN})$. Of the anthropogenic climate forcing components, the impact of the aerosol is far more uncertain in magnitude than the greenhouse gases, but potentially of equal magnitude (IPCC, 2001). Recently, the aerosol loading expressed in number concentration of fine particles has been related to adverse health effects in epidemiological studies (WHO, 2003, 2004; Ibald-Mulli et al., 2004). It is therefore important that we in an accurate and realistic way can represent aerosol sources in both local to regional air quality models, and regional to global climate models. Measurements of the aerosol emission fluxes can contribute in two important ways: they can allow us to develop accurate and efficient parameterisations of the sources, and they can help validate the emission inventories used in models. Such knowledge is necessary for assessing abatement strategies that aim at reducing particle emissions in cities.

Published by Copernicus GmbH on behalf of the European Geosciences Union. 
In the urban environment, one of the main aerosol sources is the road traffic (Ruuskanen et al., 2001; Gidhagen et al., 2005), which produces aerosols both due to the combustion of fossil fuels and due to mechanical processes, e.g. wear of break linings, tires, and road surface. To be able to include the traffic aerosol emissions in a model, we must at least be able to relate the emitted aerosols to traffic intensity. In addition, one should try to relate meteorological conditions, vehicle speed, and type of engine or fuel to the aerosol emissions quantitatively, in order to derive a source parameterisation, or different emissions factors for different conditions. This may be achieved through measurements of individual cars in the laboratory (e.g. Maricq, 1999), road tunnel studies (Gidhagen et al., 2003; Kristensson et al., 2004), by tracking individual cars in the traffic (Kittelsson et al., 2004), or by estimates based on roadside measurements (Gidhagen et al., 2004a, b; Ketzel et al., 2003). Street canyon and tunnel studies provided a significant development in urban pollution understanding by presenting pollution rates from assembles of numerous cars operating in situ. Such methods have considerable limitations and uncertainties when used to represent the actual effective emissions from a whole mixed vehicle population in an urban area.

The eddy covariance (EC) technique allows us to obtain an integral measurement of the amount of particles emitted from a wide area in the city (the footprint area could be as large as $1-10 \sim \mathrm{km}^{2}$ ) covering all sources and sinks in their natural environment. Such measurements are still scarce (Dorsey et al., 2002) but nevertheless, very useful since they give a direct measurement of the pollution source strength.

The aim of the present study is to use the eddy covariance method and thereby direct in situ flux measurements representative of the true traffic mixture covering a large geographic area to derive emission factors and if possibly a source parameterisation.

\section{Measurements}

\subsection{Campaign logistics and site description}

During 49 days, from 19 March to 6 May 2002, the turbulent aerosol particle number fluxes were measured in Stockholm, the capital of Sweden and the largest city in Sweden. The city has 750000 inhabitants and the county of Stockholm has 1.8 million inhabitants. The measurements were made from the top of a telecommunication tower in the southern central part of the city. The tower is built in concrete, hexagonal in shape and $105 \mathrm{~m}$ tall and located $28 \mathrm{~m}$ above the sea level. On the top of the tower is a 10-m tall framework. The measurement equipment was placed at the top platform of the framework, and the sampling was ejected above the platform in order to separate it from the concrete construction and minimize the flow disturbance from the tower.
The surrounding landscape varies with the point of the compass, see Fig. 1. For the analyses of the data, the area around the tower is first divided into four sectors with the size $1 \mathrm{~km} \times 1 \mathrm{~km}$ and the type of land cover will be described. This is partly motivated by the grid resolution of the traffic database, which also contain information on surface properties. For a more detailed analysis later on, each of these sectors are then divided into two sectors with the width of $45^{\circ}$, totally eight sectors.

The North East sector (NE) covers $0^{\circ}-90^{\circ}$. Fifty meter north of the tower a road with high density of traffic (32000 vehicles per day) passes in west-easterly direction. Beyond the road, $(100-400 \mathrm{~m})$ the area consists of blocks with offices, shops, streets, and car parks. Approximately $400 \mathrm{~m}$ from the tower is a road and building construction area. The area between 700 to $1000 \mathrm{~m}$ from the tower is an industrial area. Between the construction area and the industrial area there are water and a small patch of a forest. The heights of the buildings are $5-15 \mathrm{~m}$.

The South East sector (SE) covers $90^{\circ}-180^{\circ}$. The area closest to the tower consists of residential areas and smaller streets. Further away is a forest. The heights of the buildings are $15 \mathrm{~m}$ and the forest canopy (mainly spruce and pine) is $10-15 \mathrm{~m}$ high.

The South West sector (SW) covers $180^{\circ}-270^{\circ}$. Between $180^{\circ}$ and $210^{\circ}$ is a residential area. From $210^{\circ}$ up to $270^{\circ}$ an approach (ca. 85000 vehicles per day) passes through the sector in north-north-westerly direction at a distance of 800 $900 \mathrm{~m}$ from the tower. From $225^{\circ}$ to $270^{\circ}$ another road with dense traffic pass between the tower and the highway. Further away in the south-south-westerly part roads with dense traffic pass through the sector. Between the tower and the highway are residential areas. In the $220^{\circ}-250^{\circ}$ directions from the tower and beyond the highway are large sport arenas located. In the same area are also stores, offices, and a shopping centre located. Beyond the highway, at approximately $265^{\circ}-270^{\circ}$ is a roundabout with high traffic intensity. The heights of the buildings in the SW sector are 10-20 m.

The North West sector (NW) covers $270^{\circ}-360^{\circ}$. The approach and the larger road from the SW passes over bridges (62 000 vehicles per day) in the direction of $270^{\circ}-300^{\circ}$ and run into a tunnel. The same road as in the NE passes close to the tower in a west-easterly direction. Beyond this road are blocks with offices, shops, streets, and car parks, similar to those in the NE sector. Construction of a new tramline was performed in the area during the measurement campaign. At the other side of the water area is an island. This part is closer to the city centre and has more of a city centre structure, including residential areas, restaurants and shops. Many offices are located in this sector. Some of the streets have high traffic intensity and the heights of the buildings are $10-30 \mathrm{~m}$. 


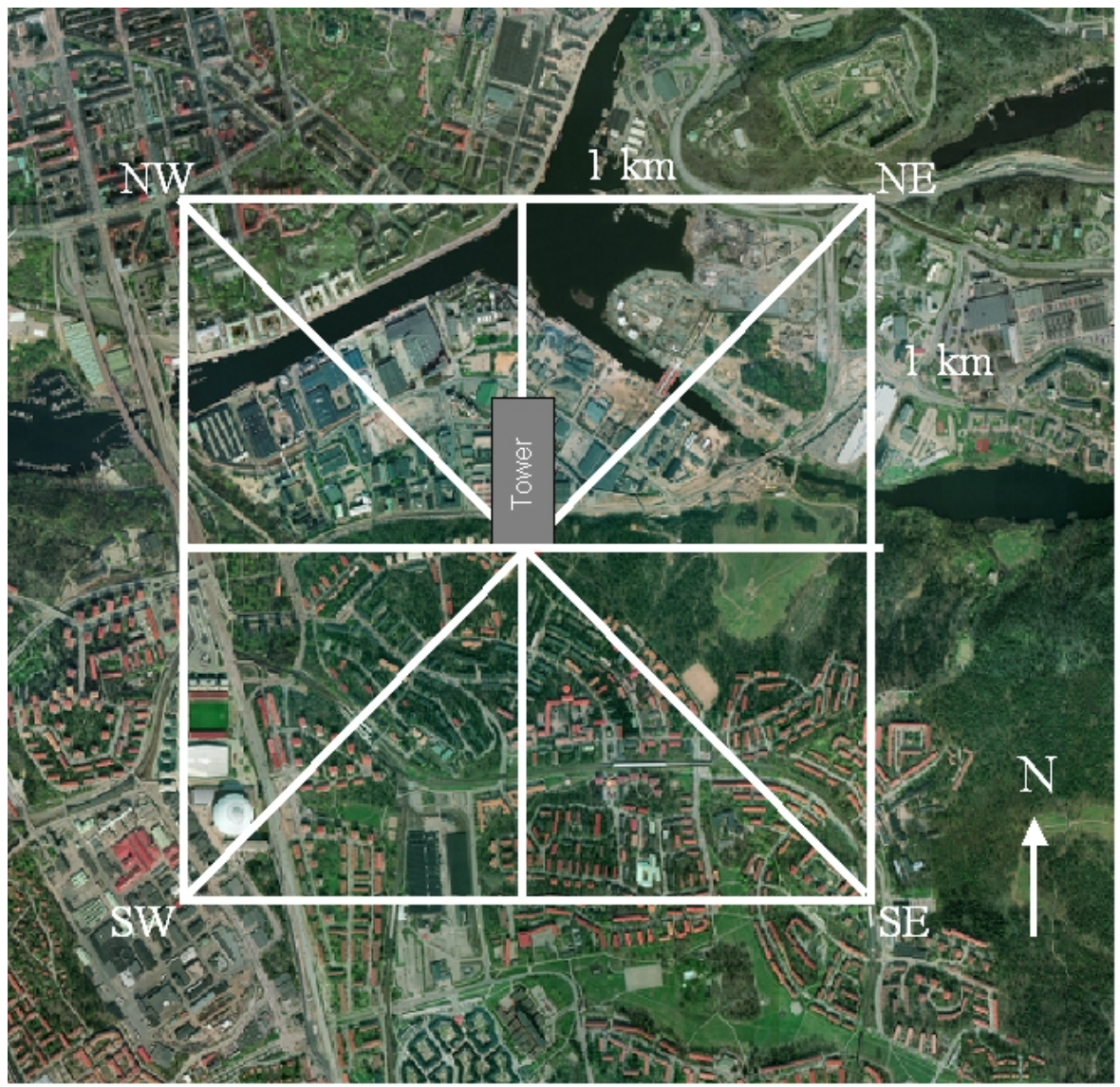

Fig. 1. Satellite photo showing the area surrounding the measurement tower, located in the centre of the photo. The sectors are North East (NE), South East (SE), South West (SW), and North West (NW), the size of the sectors are $1 \times 1 \mathrm{~km}$, these sectors are divided in $45^{\circ}$ broad sectors.

\subsection{Eddy covariance method}

The vertical aerosol number flux was calculated with the eddy covariance technique. If we separate the aerosol number concentration $N$ and the vertical wind speed $w$ in mean and turbulent fluctuations;

$N=\bar{N}+N^{\prime} \quad$ and $\quad w=\bar{w}+w^{\prime}$

where the overline - denotes temporal mean and primes ' the turbulent deviations from the mean, and use the Reynolds decomposition we can write the vertical flux;

$\overline{w N}=\bar{w} \bar{N}+\overline{w^{\prime} N^{\prime}}$

where $\bar{w} \bar{N}$ is the mean wind transport by low frequency large-scale transport and $\overline{w^{\prime} N^{\prime}}$ is the turbulent eddy transport. The turbulent flux is the covariance between fluctuations in vertical wind and in concentration, and it is the net transport that results from both sinks and sources at the surface, under the assumption that the measurements are made within the surface layer or "constant flux layer". Sensible heat $\overline{w^{\prime} T^{\prime}}$ and momentum fluxes $\overline{w^{\prime} u^{\prime}}+\overline{w^{\prime} v^{\prime}}$ (where $\mathrm{T}$ is the temperature, and $u$ and $v$ are the longitudinal and transverse horizontal wind components) are calculated in a similar manner. The fluxes were calculated over periods of $30 \mathrm{~min}$, to include the largest eddies with slow fluctuations and still exclude long-term trends in the data. A comparison for seven days has been done between fluxes calculated over half hours and hours. These fluxes agreed fairly well, with a few exceptions in the afternoons, where the hourly fluxes were lager. In addition, the hourly calculated fluxes results in a few extreme negative erratic values. The fluctuations $w^{\prime}$ and $N^{\prime}$ were separated from the mean by linear detrending, which also removes the influence of low frequency trends. Prior to the calculation of $\overline{w^{\prime} N^{\prime}}$ the wind vectors where rotated to achieve a zero $\bar{w}$, and the aerosol data was shifted in relation to the wind data to correct for the time lag in the sampling line (calculated from the maximum correlation).

The three-dimensional wind and the temperature were measured at $20 \mathrm{~Hz}$ using a Gill R3 ultrasonic research anemometer. The sonic head was extended $3.0 \mathrm{~m}$ from the measurement platform, in total located $118.0 \mathrm{~m}$ above the ground. The aerosol was sampled just beneath the sonic head through a $3.83 \mathrm{~m}$ sampling line of 1/4-inch stainless steel. 
To measure the total aerosol number concentration $\left(D_{p}>11 \mathrm{~nm}\right)$ we used a Condensation Particle Counter (CPC), model TSI 3762, which was logged through a pulseto-analogue voltage converter and one of the Gill R3 external analogue signal input lines. The sampling flow $Q$, through the CPC was $3.083 \mathrm{lmin}^{-1}$ with a bypass flow of $4.01 \mathrm{~min}^{-1}$. Losses due to Brownian diffusion and gravitational settling have been calculated. These losses together with the counting efficiency influenced only to a minor part (less than 5\%) the lower limit for the particle size. Still the lower limit of $D_{p}=11 \mathrm{~nm}$ can be used. For maximum accuracy, the correction for coincidence was determined by using the equation from TSI (2002), $N_{a}=N_{i} \exp \left(N_{a} Q \tau_{p}\right)$, where $\mathrm{N}_{a}$ is the actual number concentration, $\mathrm{N}_{i}$ is the indicated number concentration (particles $/ \mathrm{cm}^{3}$ ),$Q=51.4 \mathrm{~cm}^{3} \mathrm{~s}^{-1}$ and $\tau_{p}=0.2$ $10^{-6} \mathrm{~s}$ is the effective times each particle resides in the viewing volume. $N_{a}$ in the exponent can be approximated by $N_{i}$.

The frequency response of the CPC is limited, its firstorder response time constant $\tau_{c}$ can be tested (Buzorius, 2001), for our CPC model is $\tau_{c} \sim 0.4 \mathrm{~s}$. The underestimation of the flux due to limited sensor response depends on the frequency $f$ of the turbulence, which is determined by the observation level $z$, mean horizontal wind speed $\bar{U}$ and stratification $\mathrm{z} / L$, where $L$ is the Obukhov length. Obukhov length is a surface layer scale, with dimension meter. It is a relation between parameters characterizing dynamic, thermal and buoyant processes in the surface layer. The equation is $L=-\bar{T} U_{*}^{3} / \mathrm{kg} \bar{w}^{\prime} T^{\prime}$, where $\mathrm{k}=0.4$ is the von Kármán constant, $U_{*}$ is the friction velocity and $\mathrm{g}$ is gravitational acceleration. Hence, it expresses a competition between mechanical and convective mixing. The Obukhov length is zero for neutral stratification, positive for stable and negative for unstable stratification. If the slow response time is the principal reason for underestimating the flux, as in our case, this underestimation can easily be calculated (Buzorius et al., 2000) according to

$$
\frac{F_{m}}{F}=\frac{1}{1+\left(2 \pi n_{m} \tau_{c}\left(\frac{\bar{U}}{z}\right)\right)^{\alpha}},
$$

$F_{m}$ is the measured flux and $F$ is the flux after the correction for underestimation due to low response time and with $\alpha=1$ for stable stratification and $\alpha=7 / 8$ for neutral and unstable stratification. In Eq. (3) $n_{m}$ is the normalized frequency

$n_{m}=2.0-\frac{1.915}{1+0.5\left(\frac{z}{L}\right)}$,

for stable stratification, with the neutral limit $n_{m}=0.085$ applying also to the unstable case. The aerosol fluxes presented in this work has been corrected according to Eqs. (3) and (4). The mean correction caused by the frequency response was $8 \%$ and the median correction was $3 \%$.

Owing to the stochastic nature of the turbulence (Rannik and Vesala, 1999) and the discrete counting of aerosols (Buzorius et al., 2003) there is always an uncertainty $\delta\left(\overline{w^{\prime} N^{\prime}}\right)$ in the time averaged flux estimates. The stochastic nature of turbulence causes an uncertainty estimated to an order of magnitude of $10 \%$. According to Buzorius et al. (2003), the uncertainty in the flux, due to the discrete counting can be expressed as

$\delta\left(\overline{w^{\prime} N^{\prime}}\right)=\frac{\sigma_{w} \bar{N}}{\sqrt{\bar{N} Q \Delta t}}$

where $\sigma_{w}$ is the standard deviation of the vertical wind, $\bar{N}$ is the aerosol number concentration averaged over the sampling period $\Delta t$ (in our case $30 \mathrm{~min}$ ), and $Q$ is the sampling volume flow rate through the particle counter. The average discrete counting error was $0.54 \%$, the median $0.38 \%$ with the $25-$ 75 percentiles at $0.17 \%$ and $0.62 \%$, in summary very small errors owing to the high aerosol number concentrations.

\subsection{Traffic activity}

A grid resolved database is available with the hourly traffic activity expressed as vehicle-kilometres per time unit. This database is part of a regional air quality management system operated by the local environmental authority in the city of Stockholm and includes all types of air pollutant sources in the counties of Stockholm and Uppsala (30 different municipalities). Traffic data are based on traffic measurements on different road types during different years. The whole database is updated once a year. We have used the database for 2001 to obtain the traffic activity during the flux measurements March-May 2002. No direct real-time traffic counters were available for the measurement period.

However, from long-term observation one can expect that year-to-year variations are negligible except in areas with major changes in traffic pattern or construction areas. From 2001 to spring time in 2002, no changes in traffic pattern were reported within the spatial scales described in Fig. 1, but new constructions emerged within the footprint area in two of the sectors as it is described in this paper. While we lack point measurement of the traffic activity during the exact campaign period, we have instead a great advantage in a traffic database that gives an information representative for the average amount of traffic (vehicle kilometres) for all roads within the whole measurement sector.

The location of the measurement site in this study gives the possibility to measure fluxes from areas with different land cover, e.g. areas with densely trafficked highways, one area mainly covered with forest and residential areas. The types and number of vehicles in these areas differ over time (weekdays and holidays). The relative amounts of heavyduty vehicles (HDV) and light duty vehicles (LDV) is potentially very important for the emissions as HDV emit more particles since they are diesel fuelled (the traffic in Stockholm has $\sim 6 \% \mathrm{HDV}$ ). The vehicle speed is another factor that influences the emission. At higher speed, the vehicles emit more particles (Kittelson et al., 2004). 
Table 1. (a) Statistics values on measurement results for all sectors, for temperature $(T)$, horizontal wind speed $(U)$, friction velocity $\left(U_{*}\right)$, aerosol particle number concentration $(N)$, sensible heat flux $(H)$ and aerosol particle number flux $\left(\overline{w^{\prime} N^{\prime}}\right)$. Included is also the aerosol particle number concentration in a street canyon $\left(N_{\text {street }}\right)$ and at a rooftop $\left(N_{\text {roof }}\right)$.

\begin{tabular}{|c|c|c|c|c|c|c|c|c|}
\hline & \multicolumn{6}{|c|}{ Tower, all wind directions } & \multicolumn{2}{|c|}{ Street \& rooftop } \\
\hline & $\begin{array}{l}T \\
K\end{array}$ & $\begin{array}{c}U \\
\mathrm{~ms}^{-1}\end{array}$ & $\begin{array}{c}U_{*} \\
\mathrm{~ms}^{-1}\end{array}$ & $\begin{array}{c}N \\
\mathrm{~cm}^{-3}\end{array}$ & $\begin{array}{c}H \\
\mathrm{Wm}^{-2}\end{array}$ & $\begin{array}{c}\overline{w^{\prime} N^{\prime}} \\
10^{6} \mathrm{~m}^{-2} \mathrm{~s}^{-1}\end{array}$ & $\begin{array}{l}N_{\text {street }} \\
\mathrm{cm}^{-3}\end{array}$ & $\begin{array}{l}N_{\text {roof }} \\
\mathrm{cm}^{-3}\end{array}$ \\
\hline Mean & 278 & 6.1 & 0.38 & 5599 & 27.7 & 260 & 70845 & 10070 \\
\hline Std & 5 & 2.1 & 0.23 & 3004 & 65.4 & 422 & 46765 & 6120 \\
\hline Min & 268.7 & 0.15 & 0.01 & 1296 & -101.6 & -351 & 8540 & 2480 \\
\hline Max & 290.5 & 12.4 & 1.09 & 28247 & 293.4 & 3317 & 345100 & 68075 \\
\hline \multicolumn{9}{|c|}{ Correlations: } \\
\hline$T$ & 1.000 & 0.020 & 0.028 & -0.192 & 0.274 & -0.171 & & \\
\hline$U$ & 0.020 & 1.000 & 0.564 & -0.208 & -0.023 & 0.160 & & \\
\hline$U_{*}$ & 0.028 & 0.564 & 1.000 & 0.031 & 0.363 & 0.449 & & \\
\hline$N$ & -0.192 & -0.208 & 0.031 & 1.000 & 0.054 & 0.439 & & \\
\hline$H$ & 0.274 & -0.023 & 0.363 & 0.054 & 1.000 & 0.267 & & \\
\hline \multirow[t]{2}{*}{$\overline{w^{\prime} N^{\prime}}$} & -0.171 & 0.160 & 0.449 & 0.439 & 0.267 & 1.000 & & \\
\hline & $T$ & $U$ & $U_{*}$ & $N$ & $H$ & $\overline{w^{\prime} N^{\prime}}$ & & \\
\hline
\end{tabular}

Table 1. (b) Statistics values on measurement results for the SW and SE sectors used for the parameterisations, for temperature ( $T$ ), horizontal wind speed $(U)$, friction velocity $\left(U_{*}\right)$, aerosol particle number concentration $(N)$, sensible heat flux $(H)$ and aerosol particle number flux $\left(\overline{w^{\prime} N^{\prime}}\right)$. Included is also the aerosol particle number concentration in a street canyon $\left(N_{\text {street }}\right)$ and at a rooftop $\left(N_{\text {roof }}\right)$.

\begin{tabular}{|c|c|c|c|c|c|c|c|c|}
\hline & \multicolumn{6}{|c|}{ Tower, wind direction $90^{\circ}-270^{\circ}$} & \multicolumn{2}{|c|}{ Street \& rooftop } \\
\hline & $\begin{array}{l}T \\
\mathrm{~K}\end{array}$ & $\begin{array}{c}U \\
\mathrm{~ms}^{-1}\end{array}$ & $\begin{array}{c}U_{*} \\
\mathrm{~ms}^{-1}\end{array}$ & $\begin{array}{c}N \\
\mathrm{~cm}^{-3}\end{array}$ & $\begin{array}{c}H \\
\mathrm{Wm}^{-2}\end{array}$ & $\begin{array}{c}\overline{w^{\prime} N^{\prime}} \\
10^{6} \mathrm{~m}^{-2} \mathrm{~s}^{-1}\end{array}$ & $\begin{array}{l}N_{\text {street }} \\
\mathrm{cm}^{-3}\end{array}$ & $\begin{array}{l}N_{\text {roof }} \\
\mathrm{cm}^{-3}\end{array}$ \\
\hline Mean & 279 & 6.3 & 0.38 & 5218 & 30.2 & 153 & 70845 & 10070 \\
\hline Std & 4 & 1.9 & 0.19 & 2252 & 59.1 & 216 & 46765 & 6120 \\
\hline Min & 269.9 & 1.2 & 0.02 & 1721 & -59.0 & 1 & 8540 & 2480 \\
\hline Max & 290.4 & 11.0 & 0.96 & 21228 & 232.1 & 1185 & 345100 & 68075 \\
\hline \multicolumn{9}{|c|}{ Correlations: } \\
\hline$T$ & 1.000 & 0.135 & 0.315 & -0.155 & 0.396 & 0.024 & & \\
\hline$U$ & 0.135 & 1.000 & 0.463 & -0.147 & -0.098 & 0.030 & & \\
\hline$U_{*}$ & 0.315 & 0.463 & 1.000 & -0.045 & 0.429 & 0.384 & & \\
\hline$N$ & -0.155 & -0.147 & -0.045 & 1.000 & -0.067 & 0.448 & & \\
\hline$H$ & 0.396 & -0.098 & 0.429 & -0.067 & 1.000 & 0.274 & & \\
\hline \multirow[t]{2}{*}{$\overline{w^{\prime} N^{\prime}}$} & 0.024 & 0.030 & 0.384 & 0.448 & 0.274 & 1.000 & & \\
\hline & $T$ & $U$ & $U_{*}$ & $N$ & $H$ & $\overline{w^{\prime} N^{\prime}}$ & & \\
\hline
\end{tabular}

\subsection{Complementary measurements}

Total particle number concentrations have been measured at a roadside location, Hornsgatan (street canyon), and at an urban background location Rosenlundsgatan (Gidhagen et al., 2003). The distance between Hornsgatan and Rosenlundsgatan is $840 \mathrm{~m}$ and between Rosenlundsgatan and the tower the distance is $2500 \mathrm{~m}$, thus between Hornsgatan and the tower the distance is $3340 \mathrm{~m}$. Hornsgatan is a $24 \mathrm{~m}$ wide, four-lane street surrounded by $24 \mathrm{~m}$ high buildings on both sides, thus being a rather symmetric street canyon with a unity width/height ratio. Traffic intensity is about 35500 vehicles per day during weekdays, with an average of $5 \%$ of heavy-duty vehicles, mostly buses of which almost all uses 
ethanol for fuel. Of the light duty vehicles, there is an average of 5\% diesel fuelled cars, mainly taxis. Air intakes are placed on a trailer 1.5 from the façades, at $3 \mathrm{~m}$ height above the street surface. A CPC3022 instrument (TSI Inc.) was used to measure total number concentrations $\left(D_{p}>7 \mathrm{~nm}\right)$. An identical instrument is located at the urban background station, Rosenlundsgatan, at $30 \mathrm{~m}$ height on a roof.

\section{Results and discussion}

\subsection{Average values and covariances}

During the campaign positive upward aerosol fluxes were most frequent ( $88 \%$ of the time) and roughly an order of magnitude stronger (average value $299 \times 10^{6} \mathrm{~m}^{-2} \mathrm{~s}^{-1}$ ) compared to downward negative (deposition) fluxes (average value $26 \times 10^{6} \mathrm{~m}^{-2} \mathrm{~s}^{-1}$ ). Net deposition mainly took place during night time and times when the traffic was low. In the parkland of the SE sector net deposition fluxes occasionally occurred also during daytime. The selection of the data set representing net deposition was studied in detail within the project in a Master thesis (Brokhöj, 2003), and evaluated in conjunction with aerosol deposition models, Schack et al. (1985), Slinn (1982), and Zhang et al. (2000). The net upward fluxes were naturally also affected by deposition, although the upward source fluxes dominated. However, the fact that the net upward fluxes are an order of magnitude larger than the net downward fluxes indicates that the deposition can be neglected when studying the net upward fluxes. The comparisons with the three well-established aerosol deposition models further support this conclusion. In conclusion, the error we make by neglecting the deposition when we consider the net upward fluxes as true source fluxes is approximately $10 \%$.

Table 1 (Table 1a for all sectors and Table $1 \mathrm{~b}$ for the SW and SE sectors) summarizes the mean characteristics of key parameters measured by the EC system during the campaign, and the correlation between these parameters. Note, that the aerosol flux is better correlated with friction velocity $U_{*}$ ( $R=0.449$ ) than with the average aerosol number concentration $(R=0.439)$ when all sectors are included. It means that at $118 \mathrm{~m}$ height the turbulence at the site is an important factor for the vertical flux exchange and confirms that deposition fluxes are probably less important (since they should be dependent on aerosol number). The average number concentration is instead strongly influenced by source regions located outside the footprint A small anti correlation for the aerosol flux with temperature can be seen $(R=-0.171)$. Previous studies have seen higher aerosol concentrations at street level at low temperatures and attributed them to higher nucleation rates in the exhaust (Gidhagen et al., 2003). The traffic activity has the highest correlation with the aerosol flux $\overline{w^{\prime} N^{\prime}}$ $(R=0.788)$, when the southerly sectors are used, higher than for any of the meteorological parameters in Table 1b. More discussion about this will follow later.

Figures $2 \mathrm{a}-\mathrm{h}$ demonstrates an eight-day long period of temperature, sensible heat flux, horizontal wind speed, friction velocity (closely related to momentum flux), stability $(z / L$, where $L$ is the Obukhov length and $z$ is the measurement level), aerosol particle number flux, and aerosol number concentration and wind direction. Temperature data showed a clear diurnal cycle on most of the days being 5 to 10 degrees higher during the day compared to the night. Daily averages of air temperature increased during the campaign from the 265 to $280 \mathrm{~K}$ in the end of March up to 277 to $287 \mathrm{~K}$ in the end of April.

Sensible heat fluxes exhibited strong diurnal variation on most of the days. Horizontal mean wind speed varied from 0 to $10 \mathrm{~m} \mathrm{~s}^{-1}\left(12 \mathrm{~m} \mathrm{~s}^{-1}\right.$ if considering the entire campaign). Friction velocity being a derivative of the momentum flux varies from 0 up to about $1 \mathrm{~m} \mathrm{~s}^{-1}$ with a diurnal cycle similar to that of heat flux. Particle fluxes exhibited strong diurnal variation on most of the days. Presumably, heat flux diurnal variation is caused mainly by the diurnal cycles in solar radiation flux and atmospheric turbulence whereas particle flux depends primarily on traffic intensity within the footprint area, which varies with wind direction. For instance, on sunny weekend days heat flux has similar values to those on sunny weekdays, while particle flux is tremendously different on these days (weekend example days 110 and 111 in Fig. 2, compare Figs. $2 b$ and f. Figure $2 g$ shows that the aerosol number concentration was ranging from the $10^{3}$ to $2.5 \times 10^{4}$ particles $\mathrm{cm}^{-3}$ for the tower.

Aerosol number concentration was measured in three places: above the city at an altitude of $118 \mathrm{~m}$, inside the street canyon at $3 \mathrm{~m}$ level from the street surface and at rooftop level near the street level measurement site (Fig. 3). The roof and street level measurements were located in the northwest direction from the tower. The difference between the cutoff size, $11 \mathrm{~nm}$ for the tower and $7 \mathrm{~nm}$ for the street and roof measurements, will to a minor part be the reason for the lower concentration at the tower, because the number concentration peaks above $11 \mathrm{~nm}$ (Gidhagen et al, 2003). During some periods the correlation in aerosol time series and similarity in absolute values at the rooftop and tower sites are remarkable despite the spatial distance. Buzorius et al. (1999) demonstrated similarly high spatial homogeneity in aerosol number concentration over the distance of $2 \mathrm{~km}$ in Helsinki $(R>0.8)$ where traffic is the dominant aerosol source. Concentration time series exhibited maximal values during the day and minimum values during the night. The highest aerosol concentrations were measured at the street level, near the actual traffic source. Aerosol number was decreasing as air from the street was transported to roof level and tower level. Presumably, the mechanisms decreasing the aerosol number were mainly ventilation/dilution and to a small extent dry deposition and coagulation. Calculations presented by Gidhagen et al. (2004a) have shown 

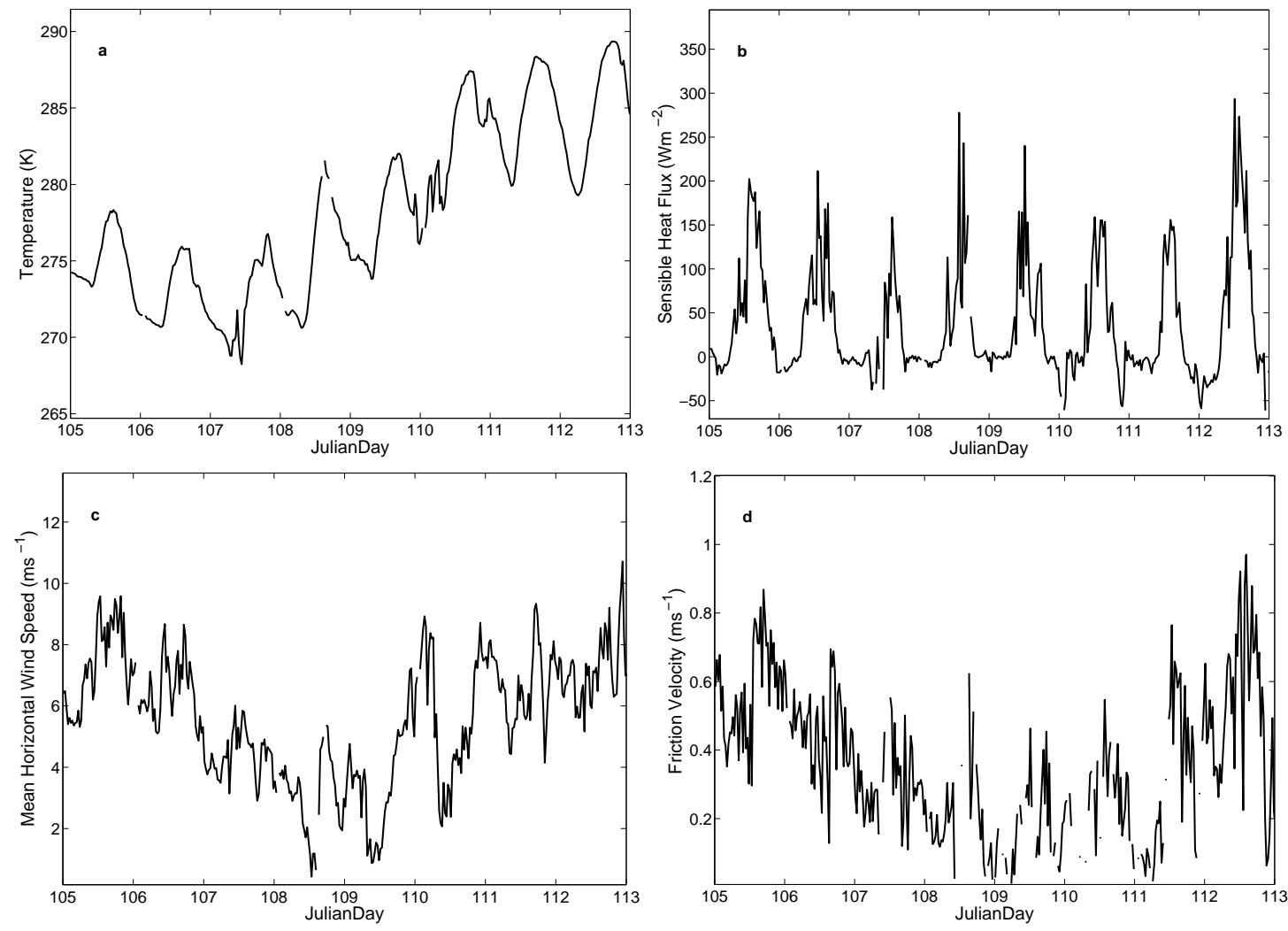

Fig. 2. Half hour means during eight days sample, Julian Day 105-112 (15-22 April), of (a) temperature, (b) sensible heat flux, (c) horizontal wind speed (d) friction velocity, (e) stability $(z / L$, where $L$ is the Obukhov length and $z$ is the measurement level), (f) aerosol particle number flux, (g) aerosol particle number concentration and (h) wind direction.

that on average the effect of coagulation and dry deposition is expected to be small $(<10 \%)$ at the levels encountered in this urban area. The ratio between the roof and tower level aerosol number concentration is in most of the cases larger than unity showing that the tower site is measuring less particles than at the rooftop site, which is closer to the aerosol sources-traffic. The ratio reaches larger values (varying from 0.5 to 12 ) at night and shows less variability during the day (from 0.7 to 3.5) due to the unstable atmosphere. During stable stratification (i.e. night-time), the atmosphere is less mixed and a larger variability in aerosol concentration is expected compared to the mixed atmosphere. Additionally the difference in time series result from different aerosol sources located in different footprint areas. If wind direction is from the roof level site to the tower, the ratio is between 0.5 and 3 .

\subsection{Spectra and co-spectra}

Figure 4 demonstrates samples of $20 \mathrm{~Hz}$ raw data. The data was acquired on 5 April 2002, from 13:00 to 13:30 local time. The half an hour time period was chosen arbitrarily. Averaged horizontal wind speed was $8.3 \mathrm{~m} \mathrm{~s}^{-1}$, standard deviation $1.78 \mathrm{~m} \mathrm{~s}^{-1}$ and friction velocity during this time period $0.87 \mathrm{~m} \mathrm{~s}^{-1}$. The atmosphere was unstable with the Obukhov length being $-353 \mathrm{~m}$. On average, the particle counter was measuring $7 \times 10^{3}$ particles $\mathrm{cm}^{-3}$ with a standard deviation of $2 \times 10^{3} \mathrm{~cm}^{-3}$. Averaged wind direction during the half an hour time period was from North $\left(20^{\circ}\right)$. Eddy covariance calculations resulted in $1200 \times 10^{6}$ particles $\mathrm{m}^{-2}$ $\mathrm{s}^{-1}$ and $170 \mathrm{Wm}^{-2}$ for aerosol and heat fluxes, respectively. Particle flux was larger during this episode compared to the study average values but has a typical value for this wind direction. Figure 4a demonstrates a high variability in aerosol concentration time series. Number concentration changes within seconds more than $100 \%$. Aerosol particles emitted from the individual sources travelling towards the sampling point have not mixed well with air parcels, which have trajectories that have not crossed the sources. It is interesting to note how at 1000 to $1100 \mathrm{~s}$ temperature and aerosol concentration was reduced and simultaneously vertical wind speed (Fig. 4c) was reduced from $2-4 \mathrm{~m} \mathrm{~s}^{-1}$ to close to zero. Before the drop, air was coming from below the measurement altitude bringing the warmer and more polluted air, which was replaced by the relative cleaner air at around $1060 \mathrm{~s}$.

All the raw data for each half hour period during the entire campaign was Fast-Fourier-Transformed for spectral and 

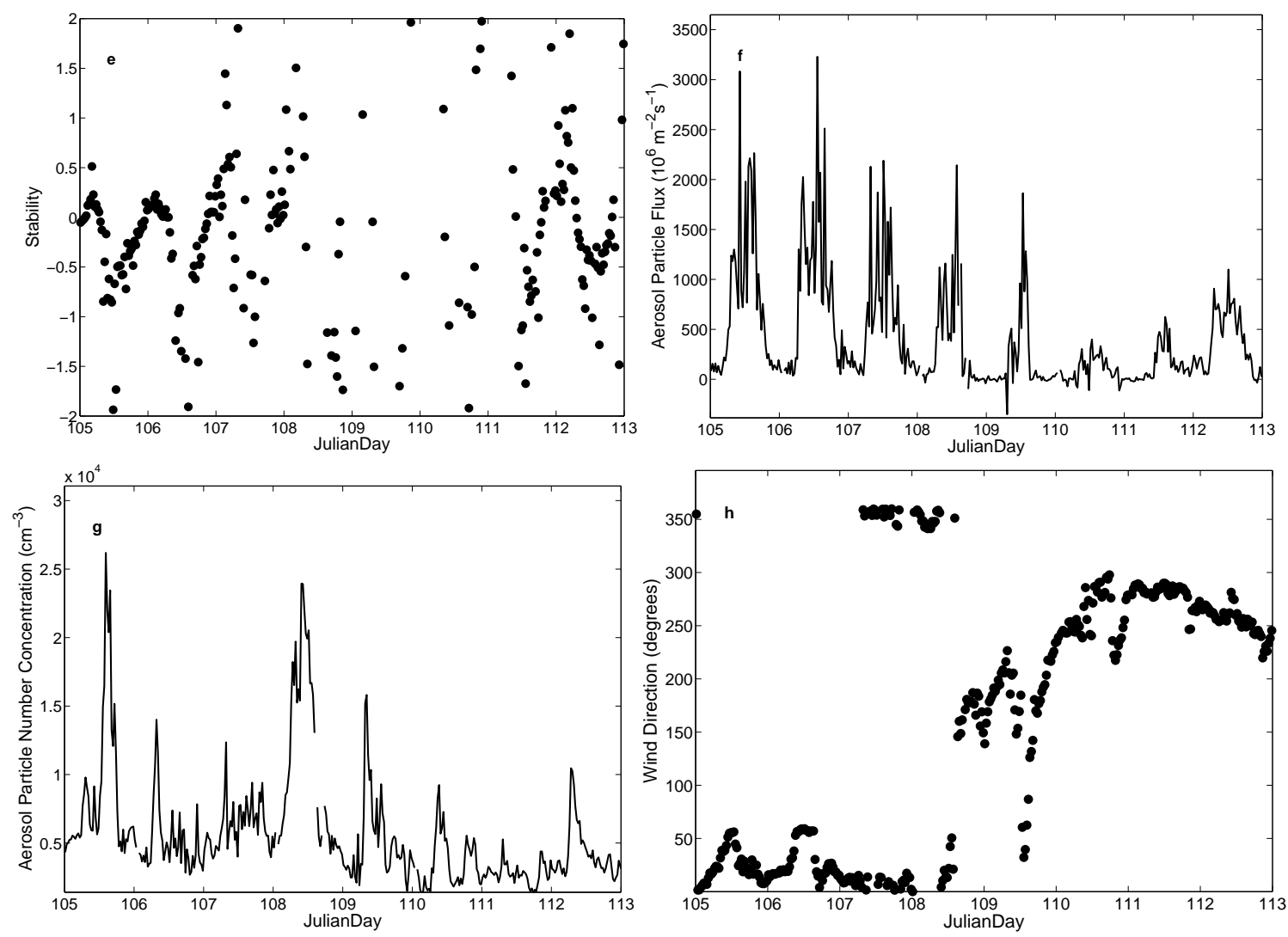

Fig. 2. Continued.

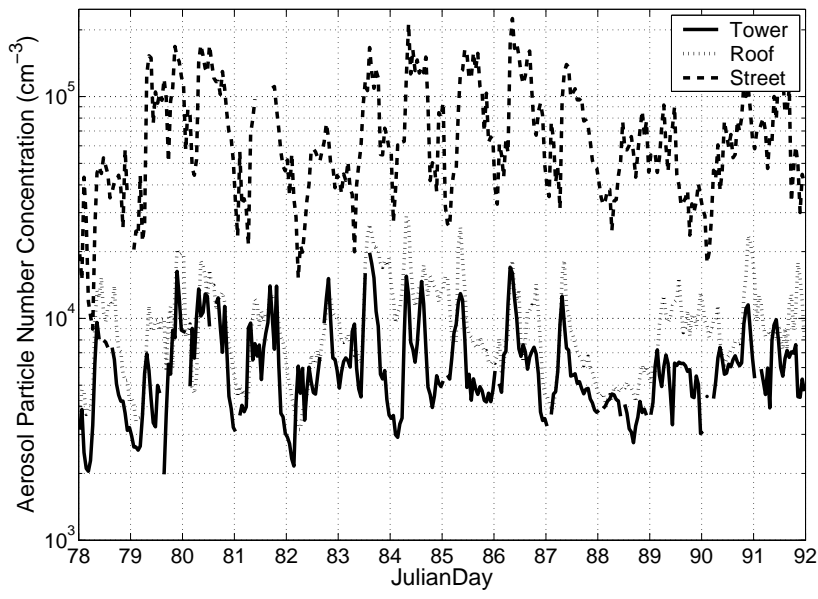

Fig. 3. Aerosol number concentration for two weeks, Julian Day 78-91, (19 March to 1 April), tower (full line), roof level in city, Rosenlundsgatan, (dotted line) and street level in city Hornsgatan (dashed line). co-spectral analysis. Results showed typical diurnal variability in the spectra - containing more energy at lower frequency range during the day compared to the nigh time. In general, spectra and co-spectra obeyed the $-2 / 3$ and $-4 / 3$ power decay laws during unstable atmospheric stratification. However, aerosol power spectra exhibited slightly faster decay than the $-2 / 3$. This is due to the limited CPC response time, attenuation in the sampling lines etc. The effect would have been greater at a lower height, but the fluxes is in any case corrected for the attenuation by the CPC using Eqs. (3) and (4). Figure 5 presents samples of spectra calculated using the raw data shown in Fig. 4.

At the low frequency range, all spectra decayed with peaks around 0.1 to $0.3 \mathrm{~s}^{-1}$ periodicity. The example of spectra in Fig. 5 (when energy decay with the lower frequency to the left of the peak) is considered to be stationary. There were many occasions when a clear peak could not be found by visual inspections of the spectra. Instead, the largest energy was contained in the lowest frequency range. Dorsey et al. (2002) reported a similar mixture of stationary and non stationary-distorted spectra in the data sampled in an urban environment.

Figure 6 demonstrates co-spectra of vertical wind speed and (a) temperature, (b) aerosol number concentration. The 


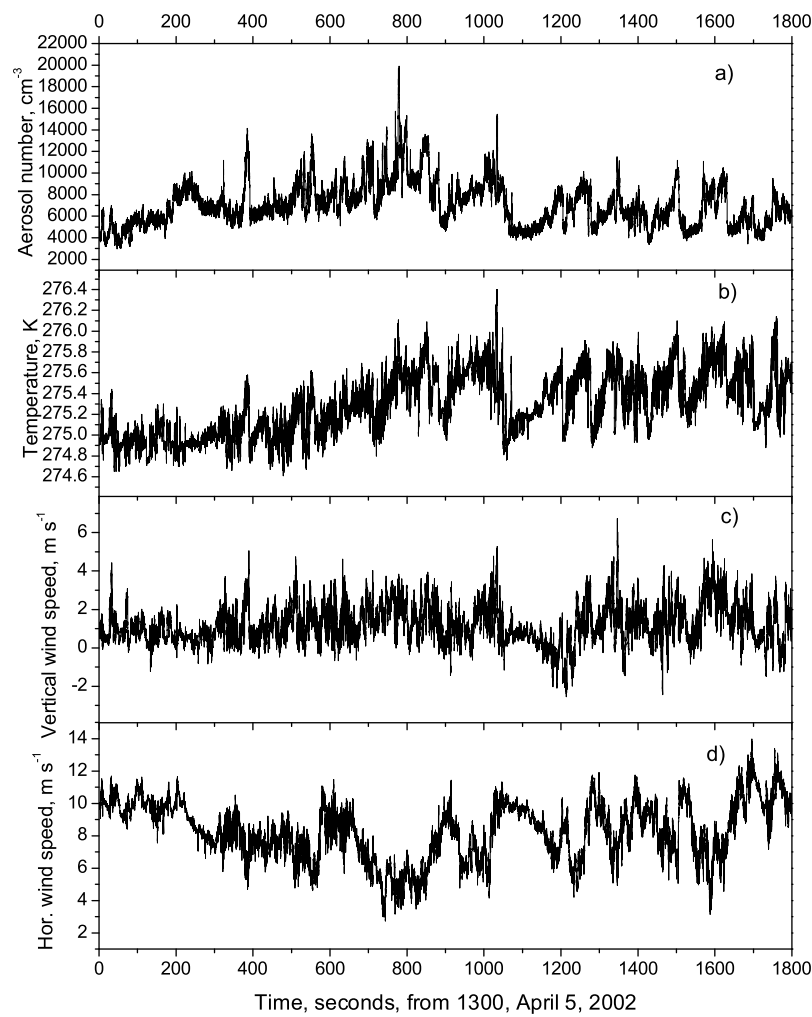

Fig. 4. Time series of (a) aerosol number concentration, (b) temperature $(\mathrm{K})$, (c) vertical wind speed and (d) horizontal wind speed.

integral under the co-spectra equals the total flux value. Most of the co-spectra values are positive indicating positive correlation and hence upward fluxes. Both co-spectra are in the inertial range decaying according to the $-4 / 3$ slope, which agrees with scaling laws. Although the aerosol power spectra in Fig. 5c decayed faster than the $-2 / 3$ indicating attenuation of the signal. Figure 6 show that the loss in the signal was not correlated with the vertical wind speed and hence had no influence in the co-spectra. Aerosol co-spectra decays with $-4 / 3$ as theory predict. Analysis on spectra and co-spectra concluded that atmospheric turbulence at the sampling site obeyed similarity scaling-laws for the surface layer and therefore the eddy covariance measurements represent surface layer exchange fluxes.

\subsection{Sources and wind direction}

The footprint area influences the magnitude of the aerosol particle flux. For a complex area such as in the urban environment, no model is yet developed and available to calculate the footprint. When such a model is developed, it will be very useful. Nevertheless, the N. Kljun's footprint model (http://footprint.kljun.net/varinput.php) has been tested. This model gives an estimate of the distance at which the contribution is largest $X_{\max }$, and the contribution within a specific

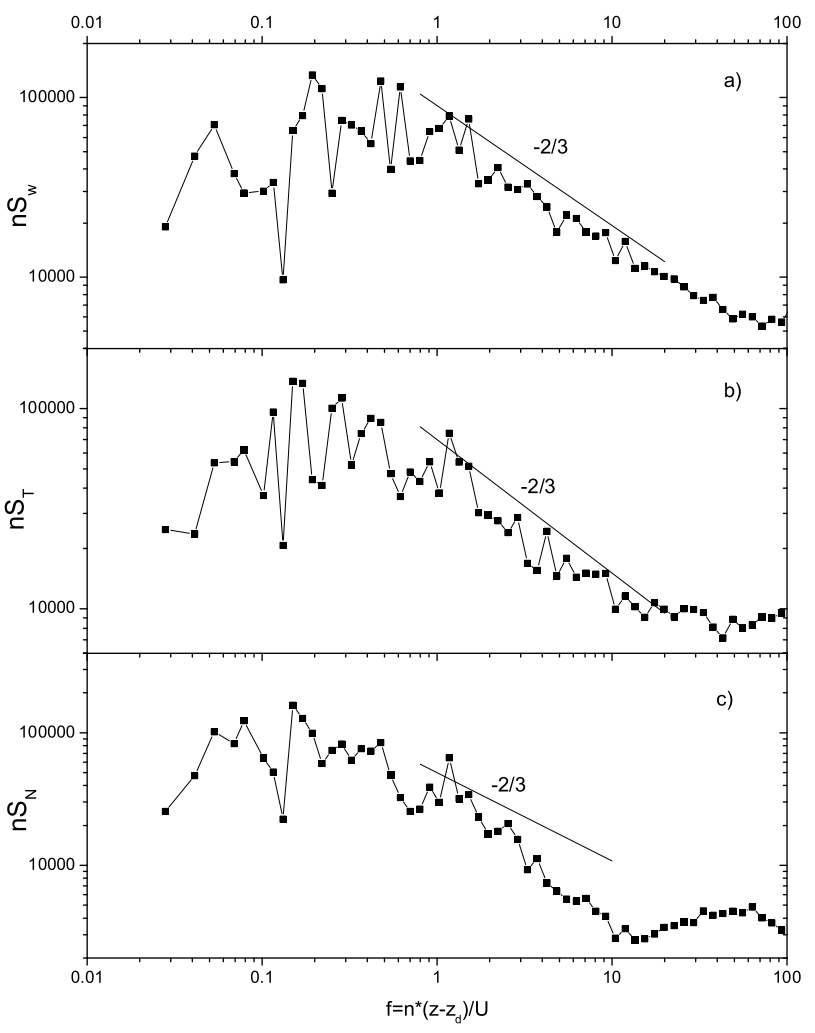

Fig. 5. Sample of (a) vertical wind speed $(w)$, (b) temperature $(T)$ and (c) aerosol number concentration $(N)$ power spectrum of the quantity marked in the index $(S)$ (normalized frequency $(f)$, frequency $(n)$, measurement height $(z)$, displacement height $\left(z_{d}\right)$, average horizontal wind speed $(U))$.

distance, $X_{75}$ representing a contribution of $75 \%$ of the flux. The model is for dynamically homogeneous terrain, which is a serious limitation at this site. Different conditions have been tested resulting in $X_{\max }$ between 860 and $1202 \mathrm{~m}$, and $X_{75}$ within 1700 and $2400 \mathrm{~m}$. The model agrees approximately with our estimates of the radius for the sectors. Even if this model calculates somewhat larger footprints than we have assumed, it is difficult to say how significant this is. Furthermore, the highway, the strongest source, is located in or close to the suggested maximal contribution point. In addition, in all sectors the traffic activity upwind are of similar magnitude within $1-2 \mathrm{~km}$, resulting in a similar average traffic activity per time and space unit even if $X_{\max }$ or $X_{75}$ changes.

As described earlier, see Fig. 1, the different sectors represent different types of land cover. Fluxes from all directions around the tower are to various degree included in the data set. Variations in the wind direction is therefore one of the reasons for the variability in the aerosol flux. The fluxes are hence sorted in eight groups depending on wind direction, each sector is $45^{\circ}$ broad. The weekdays (Monday to Friday) and holidays (Saturday, Sunday and public holidays) 


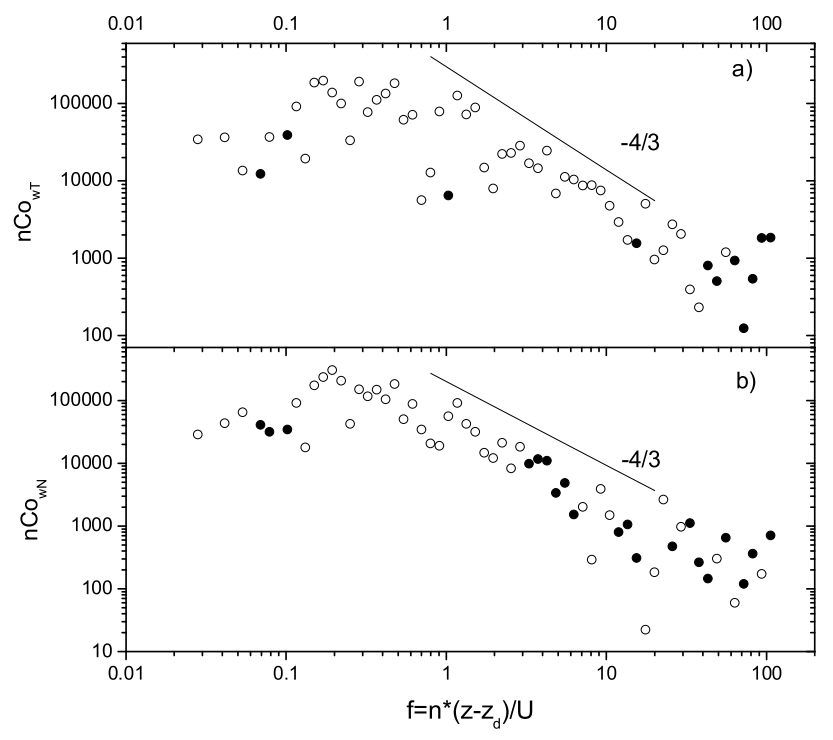

Fig. 6. Sample vertical wind speed $(w)$ and (a) temperature $(T)$, (b) aerosol number concentration $(N)$ co-spectrum of the quantity marked in the index $(\mathrm{Co})$. Open symbols mark positive values of the co-spectrum whereas solid symbols represent negative values with inverse sign, (normalized frequency $(f)$, frequency $(n)$, measurement height $(z)$, displacement height $\left(z_{d}\right)$, average horizontal wind speed $(U))$.

are treated separately. For the fluxes the mean, the median, and 25 and 75 percentiles are calculated, see Fig. 7a-b. The fluxes from that particular average wind direction includes both daytime and nighttime data.

Figure 7a shows the averaged fluxes for the 32 weekdays. The smallest fluxes with less variation were found in the sectors between $90^{\circ}$ and $225^{\circ}$. These are the sectors with residential areas, forest and only minor streets. The NE sectors had the largest mean fluxes (several hundred millions particles per square meter and second) with the highest variation. In these sectors, the footprints contained both the construction area and roads with dense traffic. From the sectors between $225^{\circ}$ and $360^{\circ}$, the fluxes were also high with a large variation. Through these sectors, an approach with dense traffic passes and the construction work was going on between $315^{\circ}$ and $360^{\circ}$.

Weekends and holidays have different particle flux characteristics. In Fig. 7b, the average fluxes during the 17 holidays are shown. The lowest fluxes came from the same sectors as during weekdays with the forest and residential area. The largest fluxes came from the areas that included larger roads. From the areas with construction work that had the largest fluxes during weekdays, the fluxes were reduced. The variations in the fluxes were much smaller during the holidays. The reason for this can be a uniform mixture of vehicles, presumably with less HDV, and the variation in the speed is less because of the absence of rush hour periods with queues
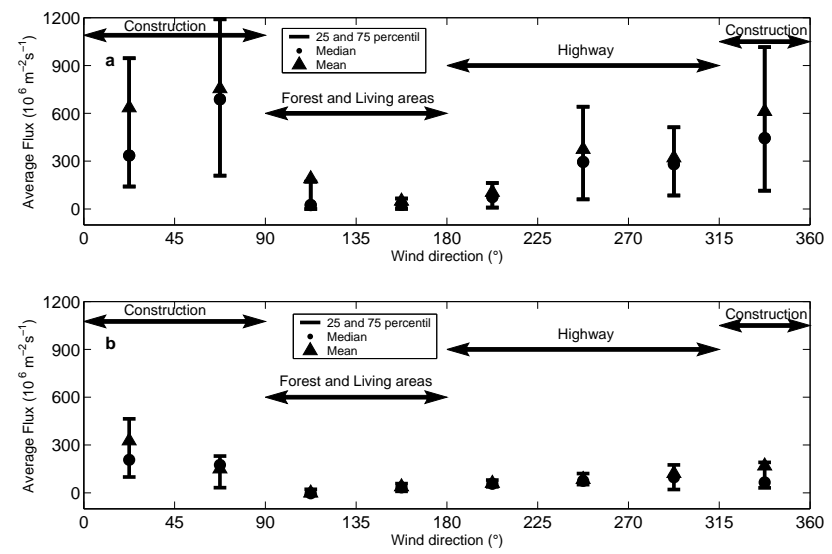

Fig. 7. Fluxes averaged over $45^{\circ}$ sectors vs. wind direction; mean flux (dots), median flux (triangles), 25 and 75 percentiles (bars). The type of land cover is marked in the panels (a) for weekdays and (b) holidays.

of cars. In the construction area the activity is smaller than during the weekdays. It appears from this first comparison that the magnitude of the aerosol source fluxes are consistent with the type of sources present in different directions assuming that traffic is the strongest available source.

\subsection{Traffic and wind direction}

The traffic database includes information about all traffic activity on the roads in the area, from the small streets in the residential area to the large highway. This spatial distribution together with the diurnal and weekly variation gives an opportunity to account for all traffic related sources influencing the emissions.

The hourly average traffic activity per area and time unit $T A$ (veh $\mathrm{km} \mathrm{m}^{-2} \mathrm{~s}^{-1}$ ) is estimated for the same eight $45^{\circ}$ broad sectors as the fluxes, Fig. 1. The traffic activities are available for both LDV and HDV, separately. Figure 8 shows the averaged traffic intensity (bars) for the eight sectors during the spring of 2001. The traffic is expected to be the same in 2002 since no significant changes had occurred in the traffic system. The gray bars show the LDV and the black bars the HDV. During holidays the total TA is reduced, the LDV traffic during holidays is $77 \%$ of the weekday $T A$ and the HDV traffic during holidays is $35 \%$ of the weekday HDV. The fraction of HDV of the total TA differs between time and sector from $2 \%$ during holidays to $8 \%$ during weekdays. The similarities between Figs. 7 and 8 supports the conclusion that the differences in flux for different wind directions are largely due to differences in traffic related sources. However, the agreement is not perfect indicating that other factors also matter. Please note that the traffic database does not consider the changed activities in the sector with the construction work, where many extra transports in and out of the area were carried out. Within this area a lot of extra of road vehicle work was performed. 


\subsection{Diurnal cycles}

The aerosol flux from the four sectors are diurnally averaged over the campaign for either the weekdays or the holidays, see Fig. 9a-d, the times are in Local Swedish Time. During weekdays, the fluxes increased sharply between 05:00 and 08:00 in all sectors with some differences between the sectors. In the SW sector the increase came earliest and in the SE sector latest, the increase is strongest in the NE sectors. The emissions during daytime have different patterns in the four sectors. In the SW sector the maximum occurs 08:30, in the NW sector around 09:30 and in the NE sector around 10:30, reaching values of about $14 \times 10^{8} \mathrm{~m}^{-2} \mathrm{~s}^{-1}$. In the cleaner SE sector, there are two modes one at 12:00 and one at 15:00 with fluxes $<2 \times 10^{8} \mathrm{~m}^{-2} \mathrm{~s}^{-1}$. In this sector, the variation over the day is less than in the other sectors. The fluxes decrease at 17:00 in the NE and SW sector, but in the NW sector not before 20:00. For all sectors except SE, the fluxes have a large variation during the day. The reason for this can be differences in the diurnal traffic activity. The high fluxes in the morning coincide with the time of the rush hour. Fluxes during the afternoon rush hour are less pronounced. In the middle of the day, however, the explanation for the relatively high emissions can be more transports carried out with HDV, due to deliveries within the areas and transports passing through, and from off-road diesel fuelled machinery. Another factor can be that with fewer cars, the driving speeds increase, and together with the increased HDV, this may result in higher emissions. Of possible importance are also the more turbulent conditions at noon when the boundary layer is fully developed. The results are in agreement with the measurements made by Dorsey et al. (2002), who observed a mid day maximum in aerosol fluxes in Edinburgh.

During holidays the diurnal cycles showed a different behaviour for three of the sectors, while in the SE sector the cycle is similar as during weekdays. The emissions were considerably lower for all sectors, the increase in the flux values during the morning was less pronounced and the maximum occurs later on the day. This is expected, as the heavy traffic is considerably lower and most people do not have to drive to their work places on holidays. The traffic is motivated more by shopping and pleasure

The average diurnal cycles during weekdays for the particle number concentration, friction velocity and heat flux during weekdays are included in Figs. 10a-b. Only the two southerly sectors are shown. At 03:00 the average background concentration is around $3000-4000 \mathrm{~cm}^{-3}$. In the morning at 08:00 a maximum in number concentrations for the day occurs. We can see a correlation with the fluxes, but the average number concentration $\bar{N}$ is more effected by the stable stratification in the morning, lower height of the boundary layer and less efficient dilution, which results in an $\bar{N}$ maximum. Friction velocity increases at the same time as the fluxes and have a maximum between 12:00 and 15:00 depending on the sector. The heat flux is negative be-

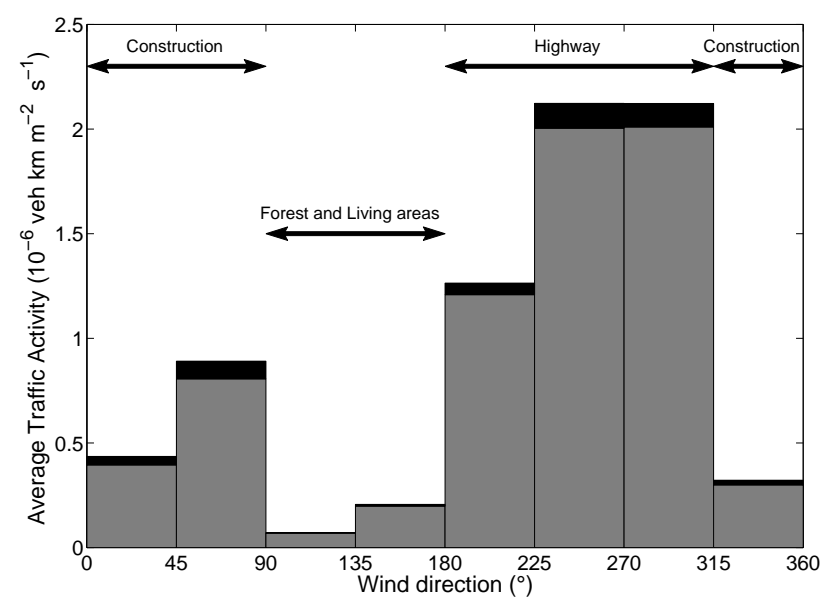

Fig. 8. Traffic activities averaged over $45^{\circ}$ sectors with the area $5 \times 10^{5} \mathrm{~m}^{2}$ vs. wind direction. Grey bars represent light duty vehicles (LDV) and black bars are heavy-duty vehicles (HDV).

fore 07:00 and after 19:00 and has a maximum in all sectors around 13:00.

Figures 11a-b show the traffic activity (LDV and HDV) compared with the particle fluxes in the SW sector for weekdays and holidays. On weekdays, Fig. 11a, the LDV traffic has two peaks, one at 08:00 and another at 17:00, this is similar for all sectors. The HDV traffic has more the shape of a mode centred at 11:00. The increase in traffic (HDV and LDV) coincides with the rise in fluxes and in the afternoon, the fluxes decrease at the same time as the reduction in the traffic activity occurs. The peaks in LDV coincide with high fluxes and at noon, the fluxes seem to be more influenced by the HDV. In the evening, there are sometimes increased fluxes at the same time as the HDV increases. For holidays, Fig. 11b, the LDV has one maximum at noon and the HDV has one morning and one afternoon peak. In the morning the fluxes coincide with the increased traffic. However, no comparison with the afternoon data can be made, due to few data points. At holiday nights and at noon the LDV is higher compared to the weekdays. For all sectors except the NW, higher emissions were observed during holiday nights than during weekday nights. There was sometimes even a small maximum in the evening, see Fig. 9. The higher fluxes during the holiday nights, as compared to weekday nights, can be an effect of the higher LDV. Especially due to the usage of taxi cars during the weekends, since these cars are often diesel fuelled.

It appears that the averaged diurnal cycles of the aerosol fluxes also support the suggestion that most of the aerosol source is related to traffic, even if we can see the influence of the turbulence when the fluxes are compared with the friction velocity. Especially in the middle of the day, when the fluxes show a strong correlation to the friction velocity, this dependency might have to be considered. 

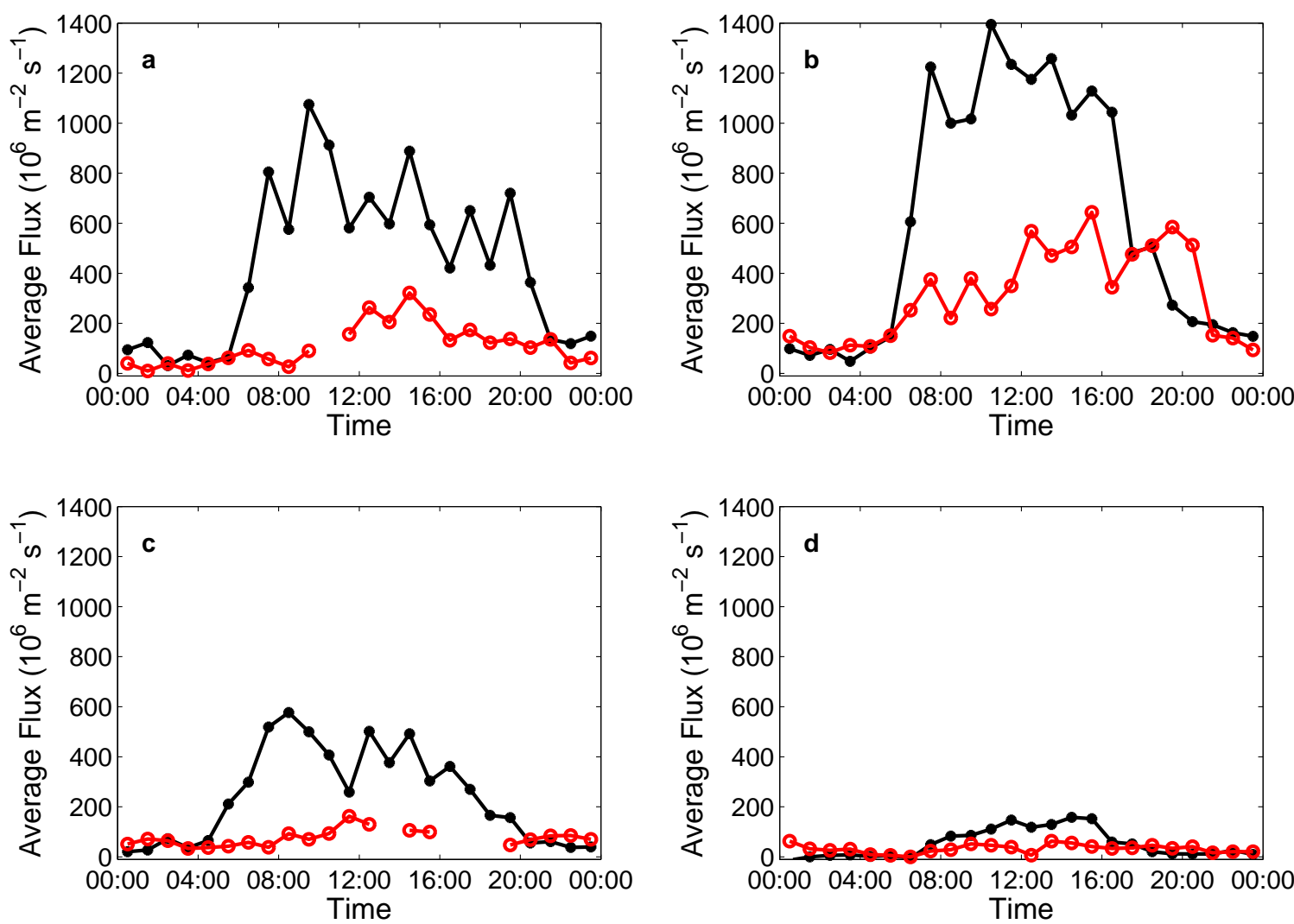

Fig. 9. Diurnal average aerosol number fluxes for four wind directions for weekdays (black lines with dots) and holidays (red lines with circles) (a) North West sector (b) North East sector, (c) South West sector and (d) South East sector.

\subsection{Source parameterisation}

According to previous discussion regarding the deposition fluxes, these can be neglected and the aerosol number source fluxes can be approximated with the measured positive upward fluxes $\overline{w^{\prime} N^{\prime}}$. In Fig. 12 the hourly averaged source fluxes (particles $\mathrm{m}^{-2} \mathrm{~s}^{-1}$ ) from wind directions between $90^{\circ}$ and $270^{\circ}$ (four $45^{\circ}$ wide sectors, Fig. 1) are shown as functions of $T A$. In total 350 data points are included from low to high TA. The north sectors are excluded due to the construction works in these sectors. Our intention is to find a first order parameterization for the urban source flux $F$. A linear fit to the data gives (see Fig. 12)

$F=E F_{f m} T A+F_{0}$

In this fit we can identify the slope as the emission factor of a mixed fleet $E F_{f m}=1.4 \pm 0.1 \times 10^{14} \mathrm{veh}^{-1} \mathrm{~km}^{-1}$. Thereby this approach, the combination of flux measurements and traffic data, offers a method to estimate the emission factor averaged over the actual vehicle population for a prolonged sampling period. Our $E F_{f m}$ compares reasonable well with previous studies, see Table 2, despite the large difference in methods.

The correlation coefficient between $\overline{w^{\prime} N^{\prime}}$ and traffic activity, $R=0.79$, which means that the explained variance of the flux is $62 \%\left(R^{2}=0.62\right)$. The aerosol number source flux is hence largely caused by traffic related emissions. The offset $F_{0}$ must represent all other sources, e.g. cooking, off-road vehicles, and other combustion sources. This source flux $F_{0}=15 \pm 18 \times 10^{6} \mathrm{~m}^{-2} \mathrm{~s}^{-1}$ is not significant larger than zero considering the $95 \%$ confidence interval of the fit. The average emissions during daytime (between 06:00 and 20:00) in $\mathrm{SW}$ are $\sim 390 \times 10^{6} \mathrm{~m}^{-2} \mathrm{~s}^{-1}$, during this time $F_{0}$ only contribute with $4 \%$ of the emissions.

To investigate the magnitude of the emissions from the construction area in the NE sector, the measured fluxes can be compared with the fluxes calculated with the emission factor for a fleet mix. The average particle flux during the whole measurement period increased with $\sim 430 \times 10^{6}$ particles $\mathrm{m}^{-2} \mathrm{~s}^{-1}$, from $F=99 \times 10^{6}$ particles $\mathrm{m}^{-2} \mathrm{~s}^{-1}$ emitted from the traffic to a measured flux of $530 \times 10^{6}$ particles $\mathrm{m}^{-2} \mathrm{~s}^{-1}$.

The friction velocity $U_{*}$ has the second best correlation $R=0.449$ with the aerosol flux when the whole data set is analysed and the third best $R=0.384$ when the data set used for the parameterisation is analysed. When we looked at the diurnal average cycles, we also found further support for the relevance of $U_{*}$. We would therefore like to combine the influence of $U_{*}$ with the linear dependency on $T A$, but keep the unit of the slope identical to that of $E F_{f m}$. We will therefore 
Table 2. Comparison with other emission factors.

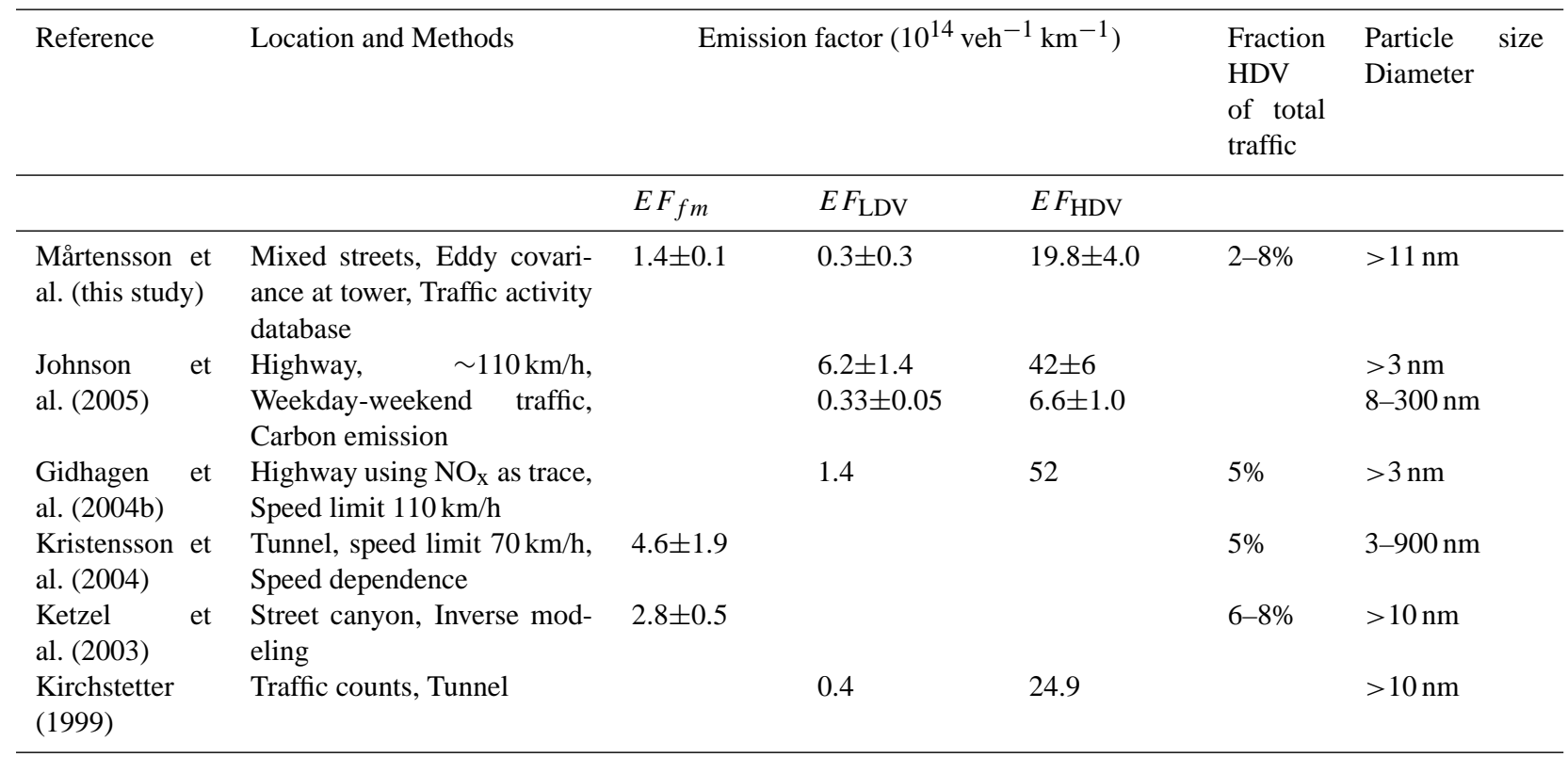

normalise $U_{*}$ with the average friction velocity $\overline{U_{*}}$. Doing so, we have found

$F=E F_{f m} T A\left(\frac{U_{*}}{\overline{U_{*}}}\right)^{0.4}+F_{0}$

Since a non-linear function of $U_{*}$ with a power coefficient of 0.4 gives a better correlation than a linear dependency. This results in a somewhat smaller $E F_{f m}=1.3 \pm 0.1 \times 10^{14} \mathrm{veh}^{-1} \mathrm{~km}^{-1}$, a larger value of $F_{0}=23 \pm 16 \times 10^{6} \mathrm{~m}^{-2} \mathrm{~s}^{-1}$, and an overall correlation $R=0.82$. The difference in $E F_{f m}$ is just barely significant, while the difference in $F_{0}$ is not significant. Despite the combination of the two best correlated factors, $T A$ and $U_{*}$, Eq. (7) is not able to explain a significantly larger part of the variation than Eq. (6). Equation (7) does a better job in predicting the daytime source flux, but overestimates the nighttime flux.

We are uncertain regarding the cause of the correlation between $F$ and $U_{*}$. A possible interpretation of the effect of $U_{*}$ is that it reflects variation in $F$ due to more or less efficient ventilation from the canopy, or turbulent transport up to the measurement level. In the later case, it would imply that the surface layer did not always extend to the measurement level. If Eq. (7) is averaged over the time, $\left(\frac{U_{*}}{\overline{U_{*}}}\right)$ will approach unity and Eqs. (7) and (6) will become identical, that is the variation in turbulent transport does not influence the average flux.

Another interpretation is related to the relationship between the actual footprints of the flux measurements, the real spatial distribution of sources and the sectors we use to derive
$T A$. The size of the footprint will be inversely dependent on $U_{*}$ (e.g. Schuepp et al., 1990). When $U_{*}$ changes, the contribution of different roads on the flux will change. This will certainly be responsible for part of the unexplained variability in the data. However, if by accident there is a systematic trend in a large part of the data that cause the footprint to move in over stronger sources when $U_{*}$ increases, it could contribute to the correlation. In either case, the inclusion of $U_{*}$ in Eq. (7) would tend to isolate the effect of the relationship between $U_{*}$ and $F$ from $T A$. Equation (6) may cause an overestimate of $E F_{f m}$ and the later smaller value resulting from Eq. (7) should be the most appropriate.

Dorsey et al. (2002) included the mean wind speed in their parameterisation of the number concentration using a dependence on the mean horizontal wind speed of the form $\bar{U}^{0.3}$, which is proportional to $U_{*}^{0.3}$. This is close to our result. We have however found a weak preference for a power equal to 0.4 . We have not been able to relate the emission factors directly to the stability, while Dorsey et al. (2002) related the number concentration to the stability with a complex function.

In Table 2 is a comparison with recently published emission factors based on different methods (road tunnel studies, inverse modelling using street canyon measurements or road side measurements). As mentioned before they have the limitation not representing the actual effective emission from a whole mixed vehicle fleet. Despite the differences in the methods, the agreement between our emission factor and literature data is fairly good. 

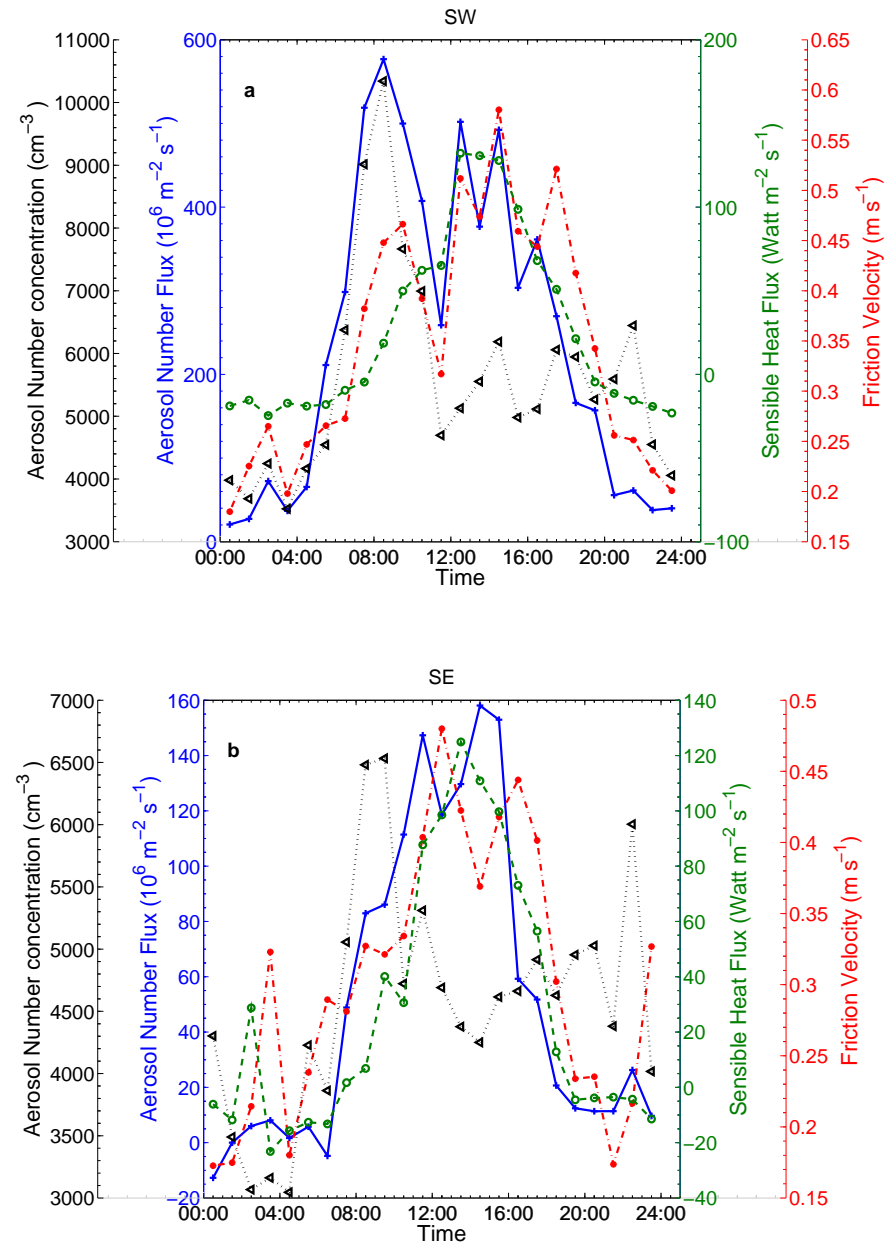

Fig. 10. Diurnal averages for weekdays for aerosol flux (blue full line with crosses), number concentration (black dotted line with triangles), sensible heat flux (dashed green line with circles) and friction velocity (red dot-dashed line with stars). (a) South West sector, (b) same as (a) but for South East sector.

As shown in Fig. 9 the fluxes are higher during weekdays then during holidays. One reason for this can be less traffic that would however not influence the emission factor. Another reason can be a different mixture of vehicles with less HDV that could have an effect on the emission factor. For this reason the diurnally averages calculated for holidays and weekdays for the four $45^{\circ}$ sectors, will be used in an attempt to find out if different parameterisations can be found for weekdays and holidays. When the averaged fluxes are combined with the $T A$, using both weekdays and holidays, the correlation coefficient increases to $R=0.85$. One reason for this is that for a specific time of the day (and $T A$ ) now only one averaged emission is available, which has reduced the variation compared to earlier attempts, when the emissions were averaged over one hour. The emission factor found using this method has the same size as with the
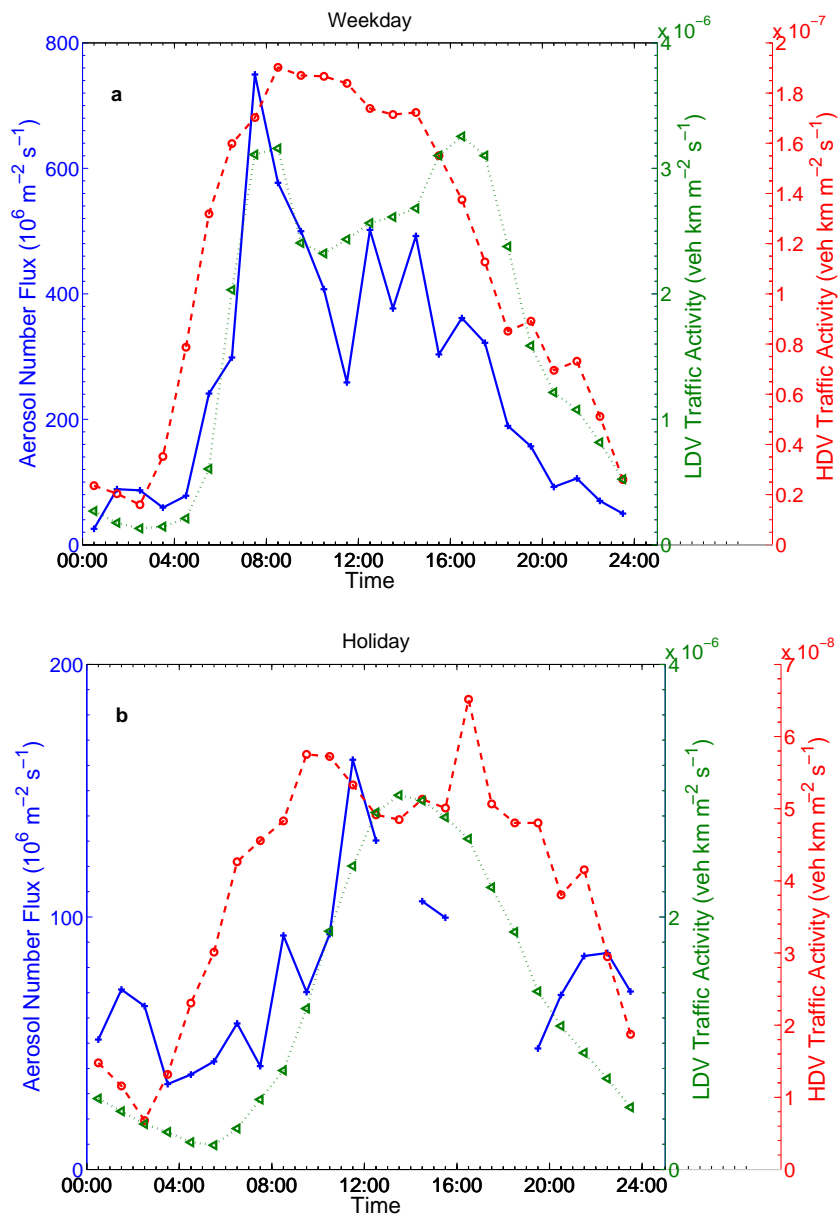

Fig. 11. Diurnal averages for the SW sector for aerosol particle number flux (blue full line with crosses), light duty vehicles traffic activity (LDV) (dotted green line with triangles, and heavy-duty vehicles (HDV) (dashed red line with circles) (a) for weekdays, (b) same as (a) but for holidays.

method using one-hour means. When the weekdays and holidays are treated separately, the emission factor is significant lower during holidays then during weekdays. The emission factor decreased from $E F_{f m}=1.410^{14} \mathrm{veh}^{-1} \mathrm{~km}^{-1}$ during weekdays to $E F_{f m}=0.410^{14} \mathrm{veh}^{-1} \mathrm{~km}^{-1}$ during holidays, i.e. only $30 \%$ of the weekday emission factor. The probably reason for this is that the HDV traffic is less during holidays as shown before in Fig. 11, where the amount of HDV during holidays are only one third of the weekday traffic.

As a final attempt to find a parameterisation, multiple linear regression techniques (Draper and Smith, 1981) will be used to examine the relationship between the LDV and HDV contribution to the emission factor. Now the urban aerosol number source flux can be written as

$F=E F_{\mathrm{LDV}} T A_{\mathrm{LDV}}+E F_{\mathrm{HDV}} T A_{\mathrm{HDV}}+F_{0}$ 
Two different emission factors are found one for LDV $\quad E F_{\mathrm{LDV}}=0.3 \pm 0.3 \times 10^{14} \mathrm{veh}^{-1} \mathrm{~km}^{-1}$, which is not significant different from zero and one for HDV $E F_{\mathrm{HDV}}=19.8 \pm 4.0 \times 10^{14} \mathrm{veh}^{-1} \mathrm{~km}^{-1}$ and $F_{0}=19 \pm 16 \times 10^{6} \mathrm{~m}^{-2} \mathrm{~s}^{-1}$, which is significant larger than zero considering the $95 \%$ confidence interval of the fit, $R=0.83$. This is in good agreement with earlier studies, see Table 2. During weekdays the HDV emit a majority of the particles, between 70 to $80 \%$, this differ over time and sector. During holidays when the HDV is reduced, around $50 \%$ of the particle emission came from HDV. In Table 3 the emissions factors are shown.

3.7 Influences of stability and friction velocity on the source parameterization

The regressions have been done for different stabilities. No significant influences depending on the stratification are found. If only data for stabilities between $-5<z / L<2$ ( $\mathrm{L}=$ Obukhov length) are included, which is true for $70 \%$ of the data finally used, the results do not change significantly, now $E F_{f m}=1.5 \pm 0.1 \times 10^{14} \mathrm{veh}^{-1} \mathrm{~km}^{-1}$, $F_{0}=14 \pm 22 \times 10^{6} \mathrm{~m}^{-2} \mathrm{~s}^{-1}$ and $\mathrm{R}=0.82$, see Table 3 for comparison. The even higher correlation for only neutral conditions $(\mathrm{R}=0.97$ for the linear regression and $\mathrm{R}=0.99$ for the multiple linear regression) does not correspond to better confidence since the numbers of data points have been reduced.

Another filtering is done due to the friction velocity, only using $U_{*}>0.2 \mathrm{~m} / \mathrm{s}$. The number of data points is then reduced from 350 to 256. This filter takes away some of the nighttime data, especially some of the small fluxes. The emission factor increases slightly to $1.5 \pm 0.1 \times 10^{14} \mathrm{veh}^{-1} \mathrm{~km}^{-1}$ and the bias is $F_{0}=24 \pm 23 \times 10^{6} \mathrm{~m}^{-2} \mathrm{~s}^{-1}$ and the correlation coefficient increase to $\mathrm{R}=0.80$. Since further data filtering does not change the results, we have chosen to keep using the larger data set.

\section{Summary and conclusions}

The measured aerosol number flux shows a good quality (considering error magnitude and turbulent spectra) and the site is high enough above the sources not to be influenced by individual buildings, point sources or vehicles. A database including traffic activity has provided a unique possibility to take into account all traffic related sources influencing the emissions. After dividing the data into subsets according to wind direction, time of the day and traffic intensity it is concluded that the strongest influence on the aerosol source fluxes is the traffic and the second strongest is the turbulent transport represented by the friction velocity $U_{*}$. A linearity between the aerosol number flux and the traffic activity results in a first simple source parameterisation, Eq. (6), which explain $62 \%$ of the variation of the flux. The corresponding

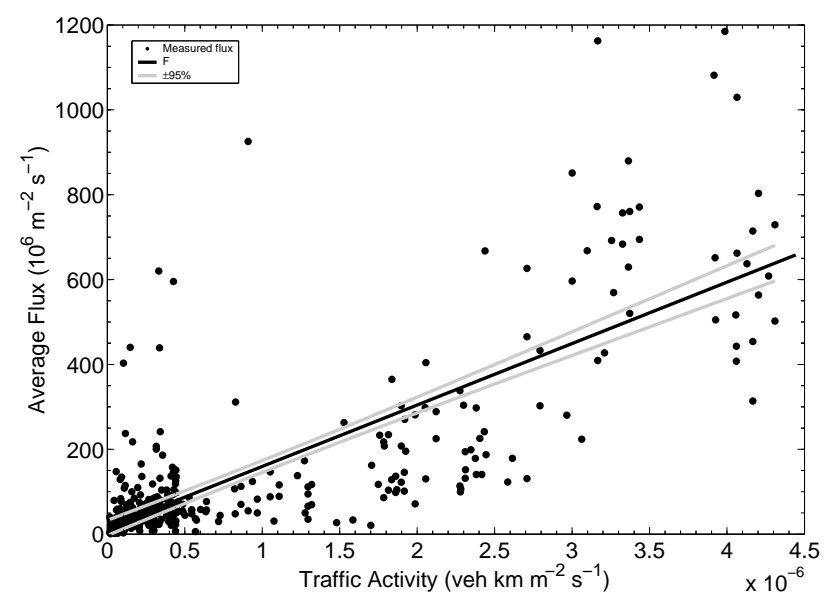

Fig. 12. Average aerosol particle fluxes as function of traffic activity (dots) and a linear fit to data black line. Grey lines are the $95 \%$ confidence intervals for the best fit to data.

emission factor $E F_{f m}=1.4 \pm 0.1 \times 10^{14}$ compares reasonably well with previous values resulting from other experiments. When we include the friction velocity $U_{*}$ in the parameterisation, Eq. (7), in order to take into account the effects of various degrees of turbulent transport or canopy ventilation, the correlation remains the same. However, it results in a slightly smaller and just barely significant reduction of $E F_{f m}$ to $1.3 \pm 0.1 \times 10^{14}$. However, the emission factor derived from Eq. (6) might be affected by periods when the surface layer did not extend to the measurements height, while the emission factor derived from Eq. (7) to some degree is corrected for such effects. If a $T A$ for a fleet mix is available the linear and simple source parameterisation in Eq. (6) is the one that should be applied in models, where of course the surface layer is perfectly defined, but one should probably apply it with the emission factor from Eq. (7). The correlation between $\overline{w^{\prime} N^{\prime}}$ and $U_{*}$ may also be an effect of changes in the footprint with $U_{*}$ and corresponding spatial differences in $T A$.

Two separate methods show that during weekdays the HDV contributed to a majority of the particle emissions. Different emission factors for weekdays and holidays are found. The ratio between these emission factors is comparable with the ratio between the HDV activity on holidays and weekdays. Finally multiple linear regression resulted in different emission factors for LDV $E F_{\mathrm{LDV}}=0.3 \pm 0.3 \times 10^{14} \mathrm{veh}^{-1} \mathrm{~km}^{-1}$ and HDV $E F_{\mathrm{HDV}}=19.8 \pm 4.0 \times 10^{14} \mathrm{veh}^{-1} \mathrm{~km}^{-1}$, Eq. (8). The fraction HDV of the total traffic activity came up to a level of $\sim 8 \%$ on the busiest roads, at this point up to $\sim 80 \%$ of the particle emissions, sometimes even more, originate from this type of traffic. Construction within an urban area increases the average aerosol number emissions, due to more of road traffic and transports mostly performed with HDV. In this study, the emission increased five times, compared to the assumed 
Table 3. Comparison between the different attempts to find a source parameterisation.

\begin{tabular}{|c|c|c|c|c|c|}
\hline \multirow[b]{2}{*}{ Linear regression } & \multicolumn{2}{|c|}{ Statistics } & \multicolumn{2}{|c|}{$\begin{array}{c}\text { Emission factor } \\
\left(10^{14} \mathrm{veh}^{-1} \mathrm{~km}^{-1}\right)\end{array}$} & \multirow{2}{*}{$\begin{array}{l}\text { Intercept } \\
F_{0} \text { with } \\
95 \% \text { confidence } \\
\text { intervals }\end{array}$} \\
\hline & $\mathrm{R}$ & $\mathrm{R}^{2}$ & $E F_{f m}$ with $95 \%$ & onfidence intervals & \\
\hline$F=E F_{f m} T A+F_{0}$ & 0.79 & 0.62 & $1.4 \pm 0.1$ & & $15 \pm 18$ \\
\hline$F=E F_{f m} T A\left(\frac{U_{*}}{U_{*}}\right)^{0.4}+F_{0}$ & 0.82 & 0.66 & $1.3 \pm 0.1$ & & $23 \pm 16$ \\
\hline \multicolumn{6}{|l|}{ Hourly means over all days } \\
\hline $\begin{array}{ll}F=E F_{f m} T A+F_{0} & \text { Week+ Holiday } \\
& \text { Week }(81) \\
& \text { Holiday }(53)\end{array}$ & $\begin{array}{l}0.85 \\
0.86 \\
0.71\end{array}$ & $\begin{array}{l}0.72 \\
0.74 \\
0.50\end{array}$ & $\begin{array}{l}1.3 \pm 0.1 \\
1.4 \pm 0.2 \\
0.4 \pm 0.1\end{array}$ & & $\begin{array}{l}13 \pm 20 \\
19 \pm 32 \\
38 \pm 9\end{array}$ \\
\hline Multiple linear regression & & & $\begin{array}{l}E F_{\mathrm{LDV}} \text { with } \\
95 \% \text { confidence } \\
\text { intervals }\end{array}$ & $\begin{array}{l}E F_{\mathrm{HDV}} \text { with } \\
95 \% \text { confidence } \\
\text { intervals }\end{array}$ & $\begin{array}{l}F_{0} \text { with } \\
95 \% \text { confidence } \\
\text { intervals }\end{array}$ \\
\hline$F=E F_{\mathrm{LDV}} T A_{\mathrm{LDV}}+E F_{\mathrm{HDV}} T A_{\mathrm{HDV}}+F_{0}$ & 0.83 & 0.70 & $0.3 \pm 0.3$ & $19.8 \pm 4.0$ & $19 \pm 16$ \\
\hline
\end{tabular}

emission from a fleet mix in the area influenced by construction. It is likely that even better correlation would have been found if the hourly variation of the traffic activity of LDV and HDV had been measured in real time during the campaign.

Although the eddy covariance method has its own errors and difficulties, we have shown that the instrumental errors and methodological errors are relatively small, partly thanks to the high aerosol number concentrations in the urban environment. One of the largest general problems with flux measurements is the question of how representative they are, since usually one measure only at one site, and this applies to our work as well as to most other studies. However, the problems associated with assumptions made when interpreting aerosol concentrations in terms of emissions, or when applying emission factors based on a very limited number of vehicles, are most probably larger. Since the flux measurements in this work were made over an extended period and has a footprint on the order of one $\mathrm{km}^{2}$, the resulting emission factors represents a truly mixed vehicle population and various weather and traffic conditions. Only counting the largest roads and bridges, approximately $10^{7}$ vehicles passed through the area during the campaign. That would be impossible to achieve with the alternative methods.

In general, important improvements can be made if future separate data sets for other periods and locations, and hence somewhat different $E F_{f m}$, can be collected and analysed. A larger and better data base, would lead to a more reliable parameterisation, and would help us to better understand the influence of meteorology, (here represented by $U_{*}$ ), and to search for an eventual temperature influence on the source fluxes. Size resolved fluxes and chemically specified fluxes (separating for instance soot from volatile compounds) would also be an important advancement in order to better understand the effects of this source, and to derive size resolved parameterizations and source fluxes for different chemical compounds.

Acknowledgements. VINNOVA, "Verket för Innovationssystem", Sweden, Project number 17418-1 and the Swedish Research Council G 5103-20005689/2000/369900 for financial support. "Telia" for the possibility to use the tower. "City of Stockholm Environment and Health Administration" for access to the traffic database. L. Bäcklin and S. van Ekeren at MISU for help with equipment and help during the measurements.

Edited by: M. Kulmala

\section{References}

Brokhöj, E.: Dry deposition of aerosol particles in the urban environment, MSc thesis at Department of Meteorology, Stockholm University, 32 pp., 2003.

Buzorius, G., Hämeri, K., Pekkanen, J., and Kulmala, M.: Spatial variation of aerosol number concentration in Helsinki city, Atmos. Environ., 33, 553-565, 1999.

Buzorius, G.: Cut-off sizes and time constants of the CPC TSI 3010 operating at 1 to $3 \mathrm{lpm}$ flow rates, Aerosol Sci. Technol., 35, 577585, 2001.

Buzorius, G., Rannik, Ü., Mäkelä, J. M., Keronen, P., Vesala, T., and Kulmala, M.: Vertical aerosol fluxes measured by the eddy covariance method and deposition of nucleation mode particles 
above a Scots pine forest in southern Finland, J. Geophys. Res., 105(D15), 19905-19916, doi:10.1029/2000JD900108, 2000.

Buzorius, G., Rannik, Ü., Nilsson, E. D., Vesala, T., and Kulmala, M.: Analysis of dry deposition velocity measurement techniques for particles smaller than $100 \mathrm{~nm}$, J. Aerosol Sci., 34, 747-764, 2003.

Dorsey, J. R., Nemitz, E., Gallagher, M. W., Fowler, D., Williams, P. I., Bower, K. N., and Beswick, K. M.: Direct measurements and parameterisation of aerosol flux, concentration and emission velocity above a city, Atmos. Environ., 36, 791-800, 2002.

Draper, N. and Smith, H.: Applied Regression Analysis, Second Edition, Wiley, 1981.

Gidhagen, L., Johansson, C., Ström, J., Kristensson, A., Swietlicki, E., Pirjolad, L., and Hansson, H.-C.: Model simulation of ultrafine particles inside a road tunnel, Atmos. Environ., 37, 2023 2036, 2003.

Gidhagen, L., Johansson, C., Langner, J., and Olivares, G.: Simulation of NOx and ultrafine particles in a street canyon in Stockholm, Sweden, Atmos. Environ., 38, 2029-2044, 2004a.

Gidhagen, L., Johansson, C., Omstedt, G., Langner, J., and Olivares, G.: Model simulations of NOx and ultrafine particles close to a Swedish highway, 2004, Environ. Sci. Technol., 38, 67306740, 2004b.

Gidhagen, L., Johansson, C., Langner, J., and Foltescu, V.: Urban scale modelling of particle number concentration in Stockholm, Atmos. Environ., 39, 1711-1725, 2005.

Ibald-Mulli, A., Timonen, K. L., Peters, A., Heinrich, J., Wölke, G., Lanki, T., Buzorius, G., Kreyling, W. G., de Hartog, J., Hoek, G., ten Brink, H. M., and Pekkanen, J.: Effects of Particulate Air Pollution on Blood Pressure and Heart Rate in Subjects with Cardiovascular Disease: A Multicenter Approach, EHP, 112, 3, 10.1289/ehp.6523, 2004.

IPCC: Climate Change 2001: The Scientific Basis, Contribution of Working Group I to the Third Assessment Report of the Intergovernmental Panel on Climate Change, edited by: Houghton, J. T., Ding, Y., Griggs, D. J., Noguer, M., van der Linden, P. J., Dai, X., Maskell, K., and Johnson, C. A., Cambridge University Press, Cambridge, United Kingdom and New York, NY, USA, 881 pp., 2001.

Johnson, J. P., Kittelson, D. B., and Watts, W. F.: Source apportionment of diesel and spark ignition exhaust aerosol using on-road data from the Minneapolis metropolitan area, Atmos. Environ., 39, 2111-2121, 2005.

Ketzel, M., Wåhlin, P., Berkowicz, R., and Palmgren, F.: Particle and trace gas emission factors under urban driving conditions in Copenhagen based on street and roof level observations, Atmos. Environ., 37, 2735-2749, 2003.

Kristensson, A., Johansson, C., Westerholm, R., Swietlicki, E., Gidhagen, L., Wideqvist, U., and Vesely, V.: Real-world traffic emission factors of gases and particles measured in a road tunnel in Stockholm, Sweden, Atmos. Environ., 38, 657-673, 2004.
Kirchstetter, T. W., Harley, R. A., Kreisberg, N. M., Stolzenburg, M. R., and Hering, S. V.: On-road measurement of fine particle and nitrogen oxide emissions from light-and heavy-duty motor vehicles, Atmos. Environ., 33, 2955-2968, 1999.

Kittelson, D. B., Watts, W. F., and Johnson, J. P.: Nanoparticle emissions on Minnesota highways, Atmos. Environ., 38, 9-19, 2004.

Maricq, M. M., Podsiadlik, D. H., and Chase, R. E.: Gasoline vehicle particle size distributions: Comparison of steady state, FTP and US06 measurements, Environ. Sci. Technol., 33, 2007-2015, 1999.

Rannik, Ü. and Vesala, T.: Autoregressive filtering versus linear detrending in estimation of fluxes by the eddy covariance method, Boundary-Layer Meteorol., 91, 259-289, 1999.

Ruuskanen, J., Tuch, Th., Ten Brik, H., Peters, A., Khlystov, A., Mirme, A., Kos, G. P. A., Brunekreef, B., Wichmann, H. E., Buzorius, G., Vallius, M., Kreyling, W. G., and Pekkanen, J.: Concentrations of ultrafine, fine and PM2.5 particles in three European cities, Atmos. Environ., 35, 3729-3738, 2001.

Schack, C. J., Pratsinis, S. E., and Friedlander, S. K.: A general correlation for deposition of suspended particles from turbulent gases to completely rough surfaces, Atmos. Environ., 19, 953960, 1985.

Schuepp, P. H., Leclerc, M. Y., Macpherson, J. I., and Desjardins, R. L.: Footprint prediction of scalar fluxes from analytical solutions of the diffusion equation, Boundary Layer Meteorol., 50, 355373, 1990.

Slinn, W. G. N.: Prediction for Particle Deposition to Vegetative Canopies, Atmos. Environ., 16, 1785-1794, 1982.

TSI: Model 3760A/3762 Condensation particle counter instruction manual, P/N 1933772, TSI Inc., St. Paul, MN, 2002.

WHO: Health aspects of air pollution with particulate matter, ozone and nitrogen dioxide, Report on a WHO working group, Copenhagen, WHO Regional Office for Europe, document EUR/03/5042688, 2003, http://www.euro.who.int/ document/e79097.pdf.

WHO: Health aspects of air pollution - answers to follow-up questions from CAFE, Report on a WHO working group, Copenhagen, WHO Regional Office for Europe, document EUR/04/5046026, 2004, http://www.euro.who.int/document/ E82790.pdf.

Wåhlin, P., Palmgren, F., and Van Dingenen, R.: Experimental studies of ultrafine particles in streets and the relationship to traffic, Atmos. Environ., 35, 63-69, 2001.

Zhang, L., Gong, S. L., Padro, J., and Barrie, L.: A size-segregated particle dry deposition scheme for an atmospheric aerosol module, Atmos. Environ., 35, 549-560, 2001. 